\title{
Nonlinear Modulation of Cutaneous Reflexes with Increasing Speed of Locomotion in Spinal Cats
}

\author{
Marie-France Hurteau, Yann Thibaudier, Charline Dambreville, Anass Chraibi, Etienne Desrochers, \\ Alessandro Telonio, and $₫$ Alain Frigon \\ Department of Pharmacology-Physiology, Faculty of Medicine and Health Sciences, Université de Sherbrooke, Sherbrooke, Quebec J1H 5N4, Canada
}

Cutaneous reflexes are important for responding rapidly to perturbations, correcting limb trajectory, and strengthening support. During locomotion, they are modulated by phase to generate functionally appropriate responses. The goal of the present study was to determine whether cutaneous reflexes and their phase-dependent modulation are altered with increasing speed and if this is accomplished at the spinal level. Four adult cats that recovered stable hindlimb locomotion after spinal transection were implanted with electrodes to record hindlimb muscle activity chronically and to stimulate the superficial peroneal nerve electrically to evoke cutaneous reflexes. The speeddependent modulation of cutaneous reflexes was assessed by evoking and characterizing ipsilateral and contralateral responses in semitendinosus, vastus lateralis, and lateral gastrocnemius muscles at four treadmill speeds: $0.2,0.4,0.6$, and $0.8 \mathrm{~m} / \mathrm{s}$. The amplitudes of ipsilateral and contralateral responses were largest at intermediate speeds of 0.4 and $0.6 \mathrm{~m} / \mathrm{s}$, followed by the slowest and fastest speeds of 0.2 and $0.8 \mathrm{~m} / \mathrm{s}$, respectively. The phase-dependent modulation of reflexes was maintained across speeds, with ipsilateral and contralateral responses peaking during the stance-to-swing transition and swing phase of the ipsilateral limb or midstance of the contralateral limb. Reflex modulation across speeds also correlated with the spatial symmetry of the locomotor pattern, but not with temporal symmetry. That the cutaneous reflex amplitude in all muscles was similarly modulated with increasing speed independently of the background level of muscle activity is consistent with a generalized premotoneuronal spinal control mechanism that could help to stabilize the locomotor pattern when changing speed.

Key words: cutaneous reflex; locomotion; speed; spinal cord

\section{Significance Statement}

When walking, receptors located in the skin respond to mechanical pressure and send signals to the CNS to correct the trajectory of the limb and to reinforce weight support. These signals produce different responses, or reflexes, if they occur when the foot is contacting the ground or in the air. This is known as phase-dependent modulation of reflexes. However, when walking at faster speeds, we do not know if and how these reflexes are changed. In the present study, we show that reflexes from the skin are modulated with speed and that this is controlled at the level of the spinal cord. This modulation could be important in preventing sensory signals from destabilizing the walking pattern.

\section{Introduction}

As the body interacts with the environment during locomotion, tactile inputs from receptors located in the skin are sent to spinal

\footnotetext{
Received Sept. 29, 2016; revised March 5, 2017; accepted March 6, 2017.

Author contributions: M.-F.H. and A.F. designed research; M.-F.H., Y.T., C.D., A.C., E.D., A.T., and A.F. performed research; M.-F.H., A.C., and A.F. analyzed data; M.-F.H., Y.T., C.D., A.C., E.D., A.T., and A.F. wrote the paper.

This work was supported by the Natural Sciences and Engineering Research Council of Canada (NSERC Discovery Grant RGPIN-2016-03790) and the American Physiological Society (Beverly Petterson Bishop Award for Excellence in Neuroscience and Arthur C. Guyton Award for Excellence in Integrative Physiology to A.F.). M.-F.H. was supported by a doctoral scholarship from NSERC. Y.T. was supported by a doctoral scholarship from the Fonds de Recherche Nature et Technologies Québec.

The authors declare no competing financial interests.

Correspondence should be addressed to Alain Frigon, Ph.D., Université de Sherbrooke, 3001, 12e Avenue Nord, Department of Pharmacology-Physiology, Faculty of Medicine and Health Sciences, Sherbrooke, Quebec J1H 5N4, Canada. E-mail: alain.frigon@usherbrooke.ca.
}

circuits to correct or reinforce the pattern. For example, when the foot/hindpaw dorsum makes contact with an obstacle, cutaneous inputs are distributed to multiple spinal motor pools to correct ipsilateral limb trajectory rapidly and reinforce contralateral limb support (Forssberg et al., 1977; Prochazka et al., 1978; Forssberg, 1979; Schillings et al., 1996; Van Wezel et al., 1997; Zehr et al., 1997; Quevedo et al., 2005). This is known as the stumbling corrective reaction. Cutaneous inputs also participate in foot/hindpaw placement, particularly as task difficulty increases (Bouyer and Rossignol, 2003a), and provide lateral stability when balance is perturbed (Bolton and Misiaszek, 2009). In spinal cats (cats with a spinal transection), in which descending supraspinal sig- 
nals are abolished, cutaneous inputs from the hindpaw are necessary for paw placement and weight bearing during hindlimb locomotion (Bouyer and Rossignol, 2003b). In decerebrate cats stepping on a treadmill or during fictive locomotion in curarized preparations, cutaneous inputs can reset the rhythm, suggesting direct access to spinal rhythm-generating circuitry (Duysens, 1977a; Duysens, 1977b; Guertin et al., 1995; Schomburg et al., 1998). Together, these studies highlight the importance of cutaneous inputs for locomotor control.

An important aspect of locomotion is the ability to change speed and/or make gait transitions for goal-oriented behaviors. An increase in locomotor speed requires changes in neural output, as shown by increases in limb muscle activity (as shown by EMG) of cats and humans (Nilsson et al., 1985; Yang and Winter, 1985; Pierotti et al., 1989; Ivanenko et al., 2006; Frigon et al., 2015). Studies in zebrafish during swimming (McLean et al., 2007; McLean et al., 2008) and mice during overground stepping (Talpalar et al., 2013; Bellardita and Kiehn, 2015) have shown that different populations of spinal neurons were recruited with increasing speed. As speed increases, interactions between somatosensory inputs and spinal locomotor circuits must also change to meet specific functional requirements. However, it is not clear how these interactions are modulated with speed.

One method to investigate speed-dependent changes in sensorimotor interactions is to evoke reflexes electrically at different treadmill speeds. A few studies have investigated cutaneous reflexes at different treadmill speeds during human locomotion (Duysens et al., 1991; Zehr et al., 1997; Hauglustaine et al., 1998; Baken et al., 2005). Although the phasedependent modulation of cutaneous reflexes appears to be largely maintained with increasing speed, it is not clear how reflex amplitude changes with speed and how responses in different muscles are affected. It should be noted that describing speed-dependent changes in cutaneous reflexes was not the main focus of these studies. Another type of reflex, the H-reflex, has been studied at different treadmill speeds in humans with equivocal results. For instance, although it was originally reported that soleus H-reflex amplitude decreased from walking to running (Capaday and Stein, 1987; Edamura et al., 1991), later studies reported a small increase when the $\mathrm{H}$-reflex was corrected for the maximal M-wave occurring in the same phase of the cycle (Simonsen and Dyhre-Poulsen, 1999; Simonsen et al., 2012). A precise analysis of reflex changes across speeds is difficult using surface electrodes because the recording and stimulating electrodes can move relative to the underlying tissue in dynamic conditions (Gerilovsky et al., 1989; Simonsen and Dyhre-Poulsen, 1999; Frigon et al., 2007).

Here, we investigated how increasing locomotor speed affects the amplitude and phase-dependent modulation of cutaneous reflexes evoked and recorded using chronically implanted electrodes in adult spinal cats. An obvious advantage of chronically implanted electrodes over surface electrodes is that muscle activity is recorded from the same part of the muscle and the sensory volley is consistent across conditions. In the present study, we address two questions: (1) is the phase-dependent modulation of cutaneous reflexes maintained across speeds? and (2) is the amplitude of evoked responses modulated with speed? The present results show how cutaneous inputs interacting with spinal circuits activate different muscles bilaterally during locomotion at different speeds.

\section{Materials and Methods}

\section{Ethical approval}

All procedures were approved by the Animal Care Committee of the Université de Sherbrooke and were in accordance with policies and directives of the Canadian Council on Animal Care. The current dataset is compiled from 4 adult cats, 3 females and 1 male, weighing between 2.5 and $5.0 \mathrm{~kg}$. As part of our effort to maximize the scientific output of each animal, three of these animals were used in other studies to investigate different scientific questions (D'Angelo et al., 2014; Dambreville et al., 2015, 2016; Hurteau et al., 2015; Frigon et al., 2017).

\section{General surgical procedures}

Surgeries were performed under aseptic conditions in an operating room with sterilized equipment. Before surgery, cats were sedated with an intramuscular injection of butorphanol $(0.4 \mathrm{mg} / \mathrm{kg})$, acepromazine $(0.1$ $\mathrm{mg} / \mathrm{kg})$, and glycopyrrolate $(0.01 \mathrm{mg} / \mathrm{kg})$. Ketamine/diazepam $(0.11$ $\mathrm{ml} / \mathrm{kg}$ in a 1:1 ratio, i.m.) was also administrated for induction. The fur overlying the back, stomach, and hindlimbs of the cats was shaved. Cats were anesthetized with isoflurane (1.5-3\%) using a mask and then intubated with a flexible endotracheal tube. Anesthesia was maintained by adjusting isoflurane concentration as needed (1.5-3\%). The level of anesthesia was confirmed and adjusted throughout the surgery by monitoring cardiac and respiratory rates, by applying pressure to the paw to detect limb withdrawal, and by evaluating jaw tone. A water-filled heating pad placed under the animal and an infrared lamp positioned $\sim 50$ $\mathrm{cm}$ over the cat kept the body temperature of the animals between $35^{\circ}$ and $37^{\circ} \mathrm{C}$, which was monitored using a rectal thermometer. An antibiotic (Convenia, $0.1 \mathrm{ml} / \mathrm{kg}$ ) was administrated subcutaneously after surgery and a transdermal fentanyl patch $(25 \mu \mathrm{g} / \mathrm{h})$ was taped to the back of the animal $2-3 \mathrm{~cm}$ rostral to the base of the tail. Buprenorphine $(0.01$ $\mathrm{mg} / \mathrm{kg}$ ), a fast-acting analgesic, was also injected subcutaneously at the end of the surgery and $\sim 7 \mathrm{~h}$ later. After surgery, cats were placed in an incubator and closely monitored until they regained consciousness. The fentanyl patch was removed 5-7 d after surgery. At the conclusion of the experiments, a lethal dose of pentobarbital was administered through the left or right cephalic vein.

\section{Spinal transection and training}

The spinal cord was completely transected (spinalization) at low thoracic levels. A small incision of the skin was made over the $12^{\text {th }}$ and $13^{\text {th }}$ thoracic vertebrae. After carefully setting aside muscle and connective tissue, a small laminectomy of the dorsal bone was made and the dura was removed. Lidocaine (xylocaine) was applied topically and two to three injections were made within the spinal cord, which was then transected with surgical scissors. Hemostatic material (Spongostan) was inserted within the gap and muscles and skin were sewn back to close the opening in anatomic layers. After spinalization, the bladder was manually expressed one to two times daily and cats were monitored by experienced personnel. The hindlimbs were cleaned by placing the lower half of the body in a warm soapy bath, as needed.

After 1 week, cats started treadmill training five times a week to recover hindlimb locomotion, with each training session lasting 20-30 min. Early after spinalization, training consisted of two experimenters moving the hindlimbs over the moving treadmill belt to reproduce a locomotor pattern, with one of the experimenters holding the tail for support. The forelimbs were positioned on a fixed platform located $1 \mathrm{~cm}$ above the belt. A Plexiglas separator was placed between the hindlimbs to prevent crossing. After a few days of training, stepping movements could be elicited by stimulating the skin of the perineal region. Over the course of a few additional weeks, cats recovered full weight-bearing hindlimb locomotion with consistent plantar placement. During data collection, an experimenter held the tail to provide equilibrium.

\section{Electromyography and nerve stimulation}

Pairs of Teflon-insulated multistrain fine wires (AS633; Cooner Wire) were directed subcutaneously from a head-mounted 34-pin connector (Omnetics) and sewn into the belly of selected hindlimb muscles for bipolar EMG. To verify electrode placement during surgery, each muscle was stimulated electrically through the appropriate head connector 
A

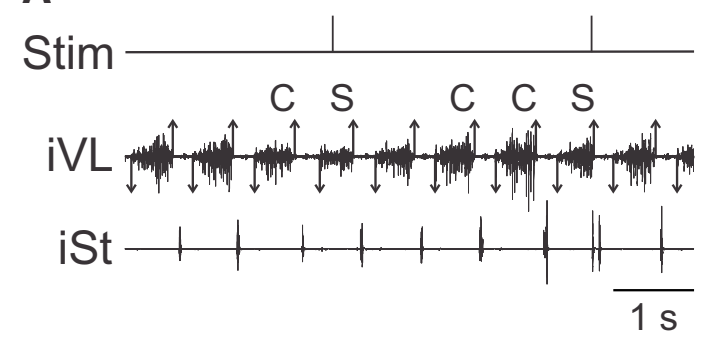

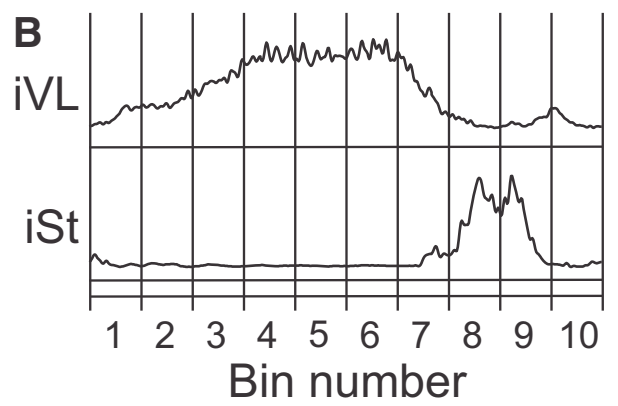

(starting on iVL onset)

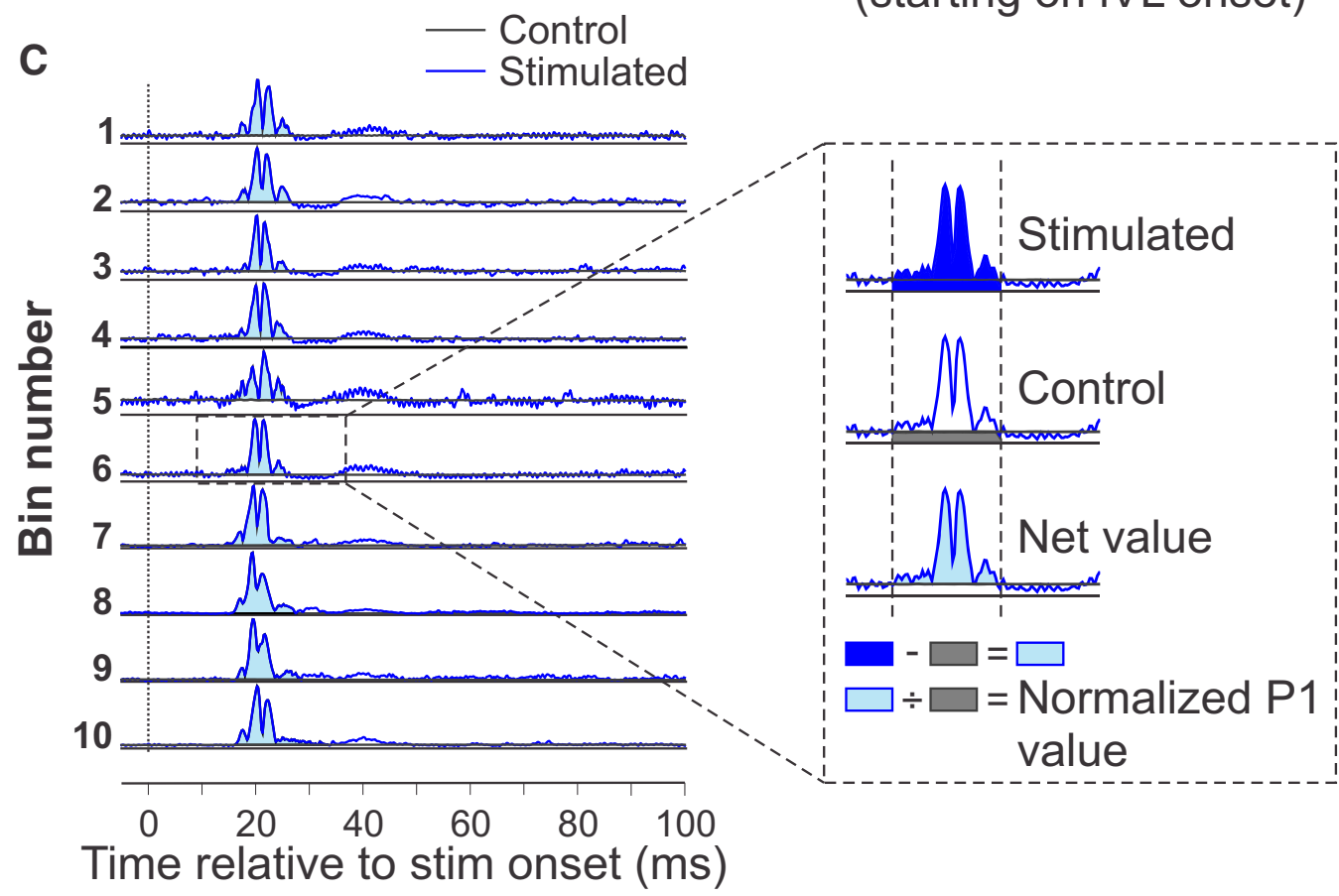

Figure 1. Reflex analysis. $\boldsymbol{A}$, Burst onsets (downward arrows) and offsets (upward arrows) of an extensor muscle ipsilateral to the stimulation were visually determined. Step cycles were defined from successive burst onsets of this extensor. Cycles were then categorized as control (C, cycles with no stimulation) or stimulated ( $S$, cycles with a stimulation). $\boldsymbol{B}$, Control and stimulated cycles were then averaged for the different muscles and normalized to the step cycle. Normalized cycles were then separated into 10 equal bins. $\boldsymbol{C}$, Control and stimulated cycles were sorted into these 10 bins. For instance, if stimuli were given in the first $10 \%$ of the cycle, then these cycles were sorted into bin 1 and so on. The control cycles provide a blEMG in each bin. The onset and offset of short-latency responses, defined as a prominent positive deflection away from the bIEMG, were then determined visually. The EMG within that window was integrated and the bIEMG occurring in the same time window was then subtracted to provide a net reflex value. This net value was then divided by the bIEMG occurring in the same time window to provide a normalized response. iVL, Ipsilateral vastus lateralis; iSt, ipsilateral semitendinosus.

channel to assess the biomechanically desired muscle contraction. The current data include EMG from the following muscles: semitendinosus (St, knee flexor/hip extensor), vastus lateralis (VL, knee extensor), and lateral gastrocnemius (LG, ankle extensor/knee flexor). During experiments, EMGs were preamplified $(10 \times$, custom-made system), band-pass filtered $(30-1000 \mathrm{~Hz})$, and amplified $(100-5000 \times)$ using a 16-channel amplifier (AM Systems Model 3500). EMG data were digitized $(5000 \mathrm{~Hz})$ with a National Instruments card (NI 6032E), acquired with custom-made acquisition software, and stored on a computer.

For nerve stimulation, pairs of Teflon-insulated multistrain fine wires (AS633; Cooner Wire) were passed through a silicon tubing. A horizontal slit was made in the tubing and wires within the tubing were stripped of their insulation. The ends protruding through the cuff were knotted to hold the wires in place and glued. The ends of the wires away from the cuff were inserted into four-pin connectors (Hirose or Samtec) for bipolar nerve stimulation. Cuff electrodes were directed subcutaneously from head-mounted connectors and placed around the left and right superficial peroneal (SP) nerves just proximal to the ankle joint.

\section{Experimental protocol}

With the forelimbs on a stationary platform, hindlimb locomotion was performed at four treadmill speeds: $0.2,0.4,0.6$, and $0.8 \mathrm{~m} / \mathrm{s}$. Each epi- sode of locomotion lasted $4-8$ min to give sufficient stimuli throughout the step cycle. To evoke reflexes, the SP nerve was stimulated electrically with a Grass $\mathrm{S} 88$ stimulator with a pulse duration of $0.2 \mathrm{~ms}$. At the start of the experiments, the motor threshold, defined as the lowest intensity required to evoke a small short latency $(7-10 \mathrm{~ms})$ response in the ipsilateral St, was identified. This was done by stimulating the SP nerve $50 \mathrm{~ms}$ after onset of the St burst ipsilateral to the stimulation, which corresponds approximately to swing onset. Stimulation intensity was then set at 1.2 times the motor threshold for the rest of the session. Threshold was again verified at the end of the session. During a trial (i.e., at one speed), 120-150 stimuli were given pseudorandomly every two to four locomotor cycles at varying delays relative to an ipsilateral extensor burst onset. The delays were adjusted as cycle duration was reduced with increasing speed to ensure that sufficient stimuli fell within the 10 bins. To deliver at least 120 stimuli every three cycles on average, an episode lasted a minimum of 360 cycles. For a given cat, all data (i.e., at the four speeds) were collected within a single session.

\section{Data analysis}

EMG and reflexes. The step-by-step procedure for quantifying reflex responses is illustrated in Figure 1. Briefly, step cycles, defined from successive bursts onsets of an ipsilateral extensor muscle, were grouped as 
stimulated or control (i.e., cycles without stimulation) cycles and divided in 10 equal subphases (bins). A minimum of 50 control cycles were averaged and separated into the 10 bins to provide a baseline locomotor EMG (blEMG) in each bin. Cycles with a stimulation were sorted into these 10 bins according to the time when the stimulation occurred within the cycle. For example, when the stimulation occurred in the first $10 \%$ of the cycle, the cycle was sorted in bin 1 and so on. The onset and offset of reflex responses, defined as a prominent positive or negative deflection away from the blEMG, were determined visually using previous studies in intact or spinal cats as a reference for setting the windows (Duysens and Loeb, 1980; Abraham et al., 1985; Loeb, 1993; Frigon and Rossignol, 2008a). The window for the short-latency excitatory (P1) and inhibitory (N1) responses started when the averaged EMG obtained from stimulated cycles was greater or smaller, respectively, than the blEMG for $>3$ ms using $95 \%$ confidence intervals and with a minimal latency of $7 \mathrm{~ms}$. Different onset latencies had to be defined because the onset of the responses differed slightly in the muscles studied and between cats. The window ended when the P1 or N1 response returned to blEMG for $>3$ $\mathrm{ms}$ or at a maximal latency of $25 \mathrm{~ms}$. Only short-latency excitatory responses were quantified because the longer-latency response (P2) starting at $\sim 25 \mathrm{~ms}$ is small or absent in spinal cats (Frigon and Rossignol, 2008a). The EMG of P1 or N1 responses within the time window was integrated and the blEMG occurring in the same time window was then subtracted to provide a net reflex value. This net value was then divided by the blEMG occurring in the same time window to evaluate reflex responses independently of the level of EMG activity (Matthews, 1986; Frigon and Rossignol, 2007, 2008a). The division is necessary to determine whether reflex amplitude scales with blEMG. For example, if the stimulated EMG had a value of 6 arbitrary units (a.u.) with a blEMG of 4 a.u., this would give a net reflex value of 2 a.u. ( 6 a.u. -4 a.u.) and a normalized value of 0.5 a.u. (2 a.u./4 a.u.) with the division. If blEMG doubled with an increase in speed to 8 a.u. and the stimulated EMG also doubled to 12 a.u., then the net reflex value would be 4 a.u. ( 8 a.u. 4 a.u.), or twice the value of 2 a.u. obtained at the slower speed. However, with the division, the normalized value is equal to $0.5 \mathrm{au}(4 \mathrm{au} / 8 \mathrm{au})$, indicating that the reflex response simply scaled with blEMG. To determine whether $\mathrm{P} 1$ or $\mathrm{N} 1$ responses were modulated with phase and as a function of speed, short-latency responses in a given muscle were expressed as a percentage of the maximal $\mathrm{P} 1$ value obtained in 1 of the 10 phases at $0.4 \mathrm{~m} / \mathrm{s}$ because all maximal responses were observed at this speed. To evaluate the effect of speed on the phase-dependent modulation of short-latency responses, a modulation index was calculated by measuring the difference between the largest and smallest responses out of the 10 bins.

To characterize the mean amplitude of EMG bursts, the first 20-30 consecutive cycles were selected at each speed. Burst onsets and offsets of selected muscles were determined by visual inspection by the same experimenter (M.-F.H.) from the raw EMG waveforms using a custommade program. Mean EMG amplitude was measured by integrating the full-wave rectified EMG burst from onset to offset and dividing it by its burst duration.

Kinematics. During experiments, two cameras (Basler AcA640-100 $\mathrm{gm})$ captured videos of the left and right sides at 60 frames/s with a spatial resolution of 640 by 480 pixels. Images were acquired by a custom-made Labview program and synchronized with the EMG. Custom-made software was used to analyze videos offline at 60 frames/s. All speeds for a given cat were tested on the same day. At every speed, the first 20-30 consecutive cycles (the same as the ones used for mean EMG amplitude) were used to measure temporal and spatial parameters. Stance onset was defined as the first frame where the paw made visible contact with the treadmill surface; stance offset (or swing onset) was defined as the frame with the most caudal displacement of the limb. Cycle duration corresponded to the interval of time between successive stance onsets of the same limb. The temporal phase interval was measured as the interval of time between stance onsets of the right and left hindlimbs divided by right hindlimb cycle duration. To measure the step-by-step consistency of temporal coordination between the left and right hindlimbs, a temporal phasing index was calculated by measuring the absolute deviation of the temporal phase interval from a perfect symmetry of 0.5 .
Stride length was measured as the horizontal distance traveled from stance offset to onset plus the distance traveled by the contralateral treadmill belt during the swing phase (swing duration multiplied by treadmill speed) (Goetz et al., 2012; Thibaudier and Frigon, 2014). Step length was measured as the distance between the leading and trailing limb at stance onset of the leading limb (Hoogkamer et al., 2014). A spatial analog of the temporal phase interval, the gap interval, was measured by dividing right hindlimb step length by right hindlimb stride length (Abourachid et al., 2007; Thibaudier and Frigon, 2014). To measure the step-by-step consistency of spatial coordination between the left and right hindlimbs, a spatial phasing index was calculated by measuring the absolute deviation of the gap interval from a perfect symmetry of 0.5 .

\section{Statistical analysis}

A one-factor (speed) repeated-measures ANOVA was used to compare the mean EMG amplitude, cycle duration, phase durations, temporal phasing, reflex modulation index, temporal phase index, and spatial gap index across speeds for the group $(n=4$ cats) or for pooled data $(n=$ number of nerves stimulated). Pairwise comparisons were then performed when a significant main effect of speed was found. Significance level was set at $p<0.05$.

\section{Results}

The aim of this study was to investigate how cutaneous reflexes are affected by a change in locomotor speed in spinal cats using chronic implantations. Spinal cats were used because they perform consistent stepping over a range of speeds (Forssberg et al., 1980a, 1980b; Dambreville et al., 2015; Frigon et al., 2017), the phase-dependent modulation of cutaneous reflexes is well documented (Forssberg et al., 1977; LaBella et al., 1992; Frigon and Rossignol, 2008a, 2008b, 2009), and complex influences from supraspinal structures are removed. Cats recovered stable hindlimb locomotion 6-10 weeks after spinalization. During experiments, the hindlimbs stepped at treadmill speeds of $0.2,0.4,0.6$, and 0.8 $\mathrm{m} / \mathrm{s}$ while the left or right SP nerve was electrically stimulated to assess the phase-dependent modulation of reflexes and to measure response amplitude in three hindlimb muscles bilaterally. Spinal cats can adjust to different treadmill speeds because of load-sensitive feedback from muscle and cutaneous afferents (Duysens et al., 2000; Rossignol and Frigon, 2011).

\section{Modulation of the locomotor pattern with speed}

It has been well established that EMG burst durations and amplitudes in hindlimb muscles are altered by increasing treadmill speed in intact and spinal cats (Pierotti et al., 1989; Dambreville et al., 2015; Frigon et al., 2015, 2017), as well as in leg muscles of human subjects (Grillner et al., 1979; Nilsson et al., 1985; Yang and Winter, 1985; Ivanenko et al., 2006). A characterization of the EMG pattern is important because changes in cutaneous reflexes with increasing speed could be due in large part to corresponding changes in the underlying level of background EMG activity, an estimation of the underlying excitability of the motoneuronal pool. Figure 2 shows the EMG activity of selected hindlimb muscles in one spinal cat stepping at treadmill speeds of $0.2,0.4,0.6$, and $0.8 \mathrm{~m} / \mathrm{s}$ (Fig. $2 A$ ) and the mean amplitude of EMG bursts for the muscles (St, VL, and LG) where cutaneous reflexes were measured for individual cats and for the group (Fig. $2 B$ ). As speed increased, the burst duration of extensors (VL and LG) was visibly reduced, whereas that of St remained unchanged. Conversely, EMG burst amplitude increased in all three muscles with increasing speed. The increase in mean EMG amplitude was significant $(p<0.05)$ for VL and LG. As expected, cycle and stance durations decreased significantly as speed increased $(p<$ $0.01)$, whereas swing phase duration remained unaffected $(p>$ 0.05 ) (Fig. 2C). The phasing between the left and right hindlimbs 
A

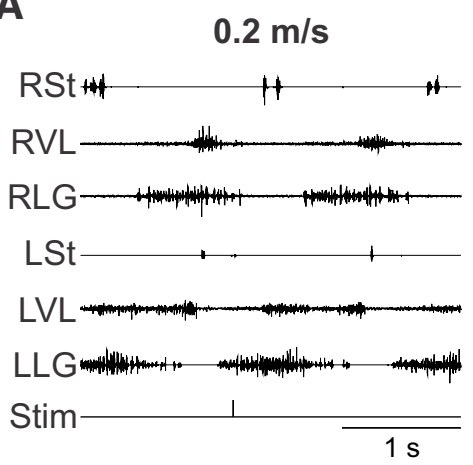

\section{$0.6 \mathrm{~m} / \mathrm{s}$}

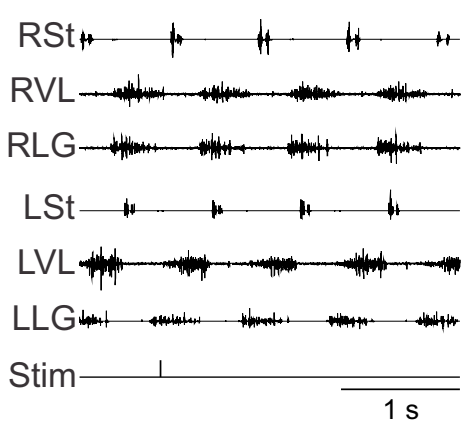

$0.4 \mathrm{~m} / \mathrm{s}$
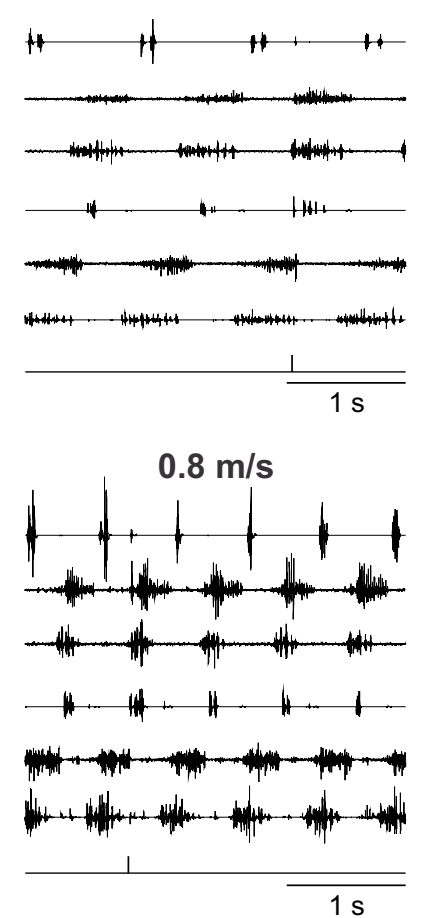

B
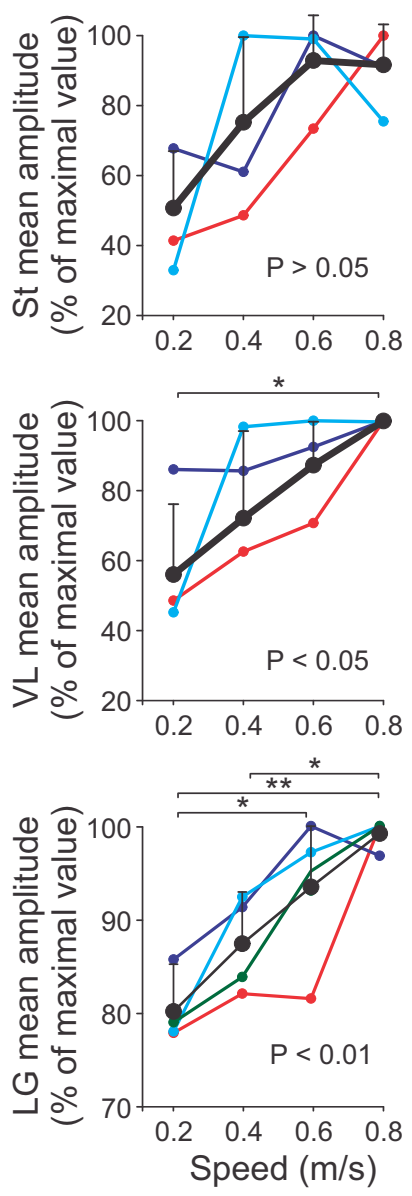

$\rightarrow$ Cat 1

$\rightarrow$ Cat 2

$\rightarrow$ Cat 3

$\rightarrow$ Cat 4

- Mean
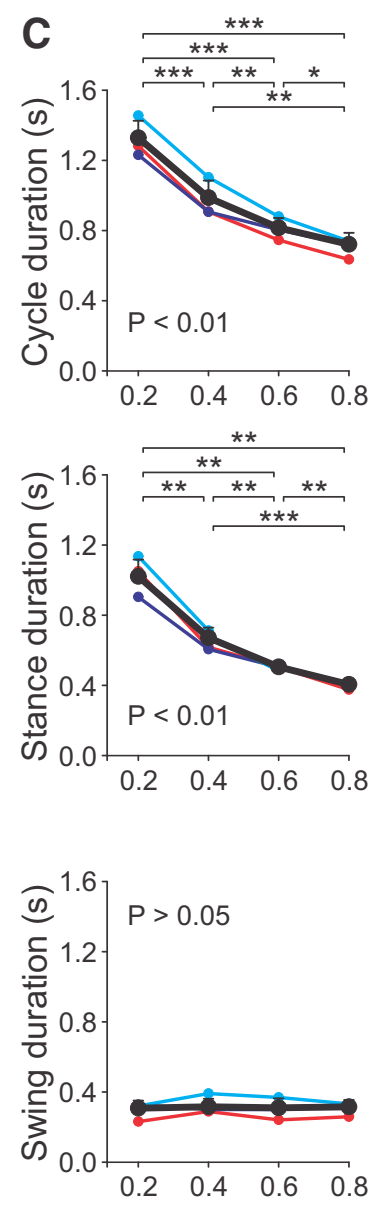

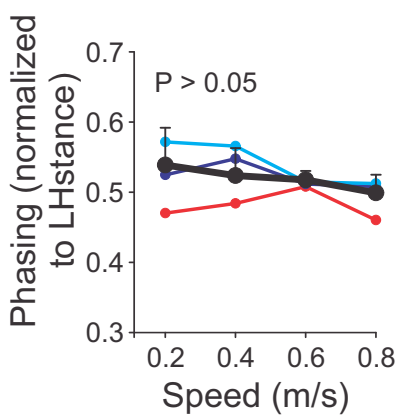

Figure 2. Modulation of the locomotor pattern with increasing speed. $A$, Each panel shows the EMG from the right (R) and left (L) St, VL, and LG. The stimulation (Stim) of the left SP nerve is shown below the EMGs. Data are from Cat 4. B, Mean amplitude of the St, VL, and LG EMG bursts normalized to the maximal value obtained at one speed. $\boldsymbol{C}$, Cycle, stance, and swing durations and temporal phasing at the different speeds. Data are shown for individual cats and for the group ( $n=4$ cats). $p$-values indicate if there was a significant effect of speed (one-factor repeated-measures ANOVA) at the 0.05 level. Asterisks indicate significant differences between speeds (pairwise comparisons): ${ }^{*} p<0.05 ;{ }^{* *} p<0.01 ;{ }^{* * *} p<0.001$.

was close to 0.5 , or a strict out-of-phase alternation, and was not significantly affected by speed $(p>0.05)$. Electrical stimuli to the SP nerve at $1.2 \mathrm{~T}$ did not visibly affect the ongoing locomotor pattern.

\section{Modulation of ipsilateral responses with speed}

In intact cats, cutaneous reflexes, evoked by electrical stimulation of a peripheral nerve, generally consist of a short-latency (7-10 $\mathrm{ms}$ ) excitatory response, termed $\mathrm{P} 1$, followed by a longer-latency (20-25 ms) excitatory response, termed P2, in ipsilateral flexor muscles during their period of activity (Duysens and Loeb, 1980; Abraham et al., 1985; Pratt and Loeb, 1991; Pratt et al., 1991; Loeb, 1993; Frigon and Rossignol, 2007; Frigon et al., 2009). In ipsilateral extensor muscles, cutaneous reflexes generally consist of a short-latency inhibitory response, termed N1, followed by a P2 or P3 response during their period of activity. In spinal cats, although the pattern of cutaneous reflex responses is similar to intact cats, P2 responses are generally smaller or absent and N1 responses in extensors are reduced and can even be replaced by P1 responses (Frigon and Rossignol, 2008a, 2008b).

To investigate the phase-and speed-dependent modulation of cutaneous reflexes in muscles with different biomechanical actions and crossing different joints, we stimulated the SP nerve at different times during the step cycle and recorded responses in the ipsilateral St (Fig. 3), VL (Fig. 4), and LG (Fig. 5) muscles at four different speeds. Figures $3 A, 4 A$, and $5 A$ show averaged traces in each of the 10 bins in one spinal cat at two treadmill speeds: 0.4 and $0.8 \mathrm{~m} / \mathrm{s}$. Figures $3 B, 4 B$, and $5 B$ show the ampli- 


\section{Ipsilateral Semitendinosus}
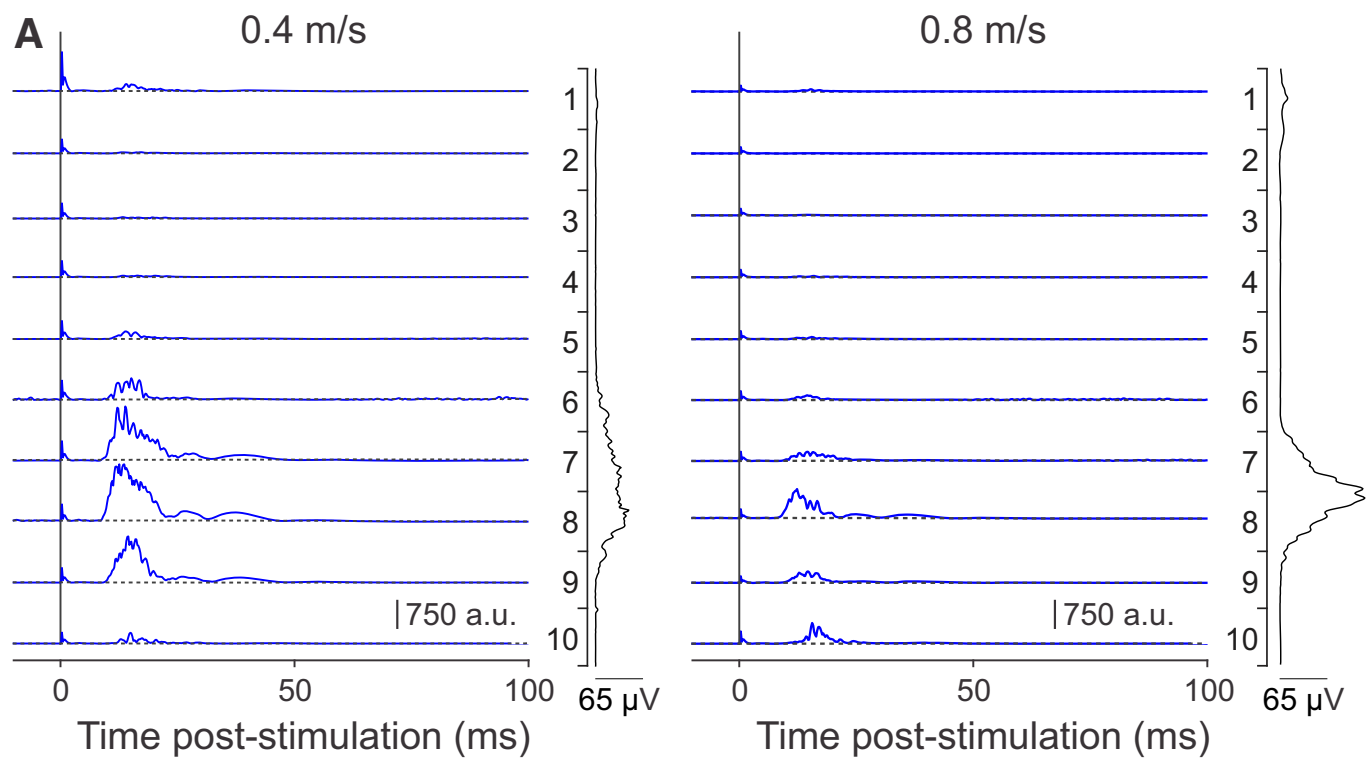

B

$0.2 \mathrm{~m} / \mathrm{s}$
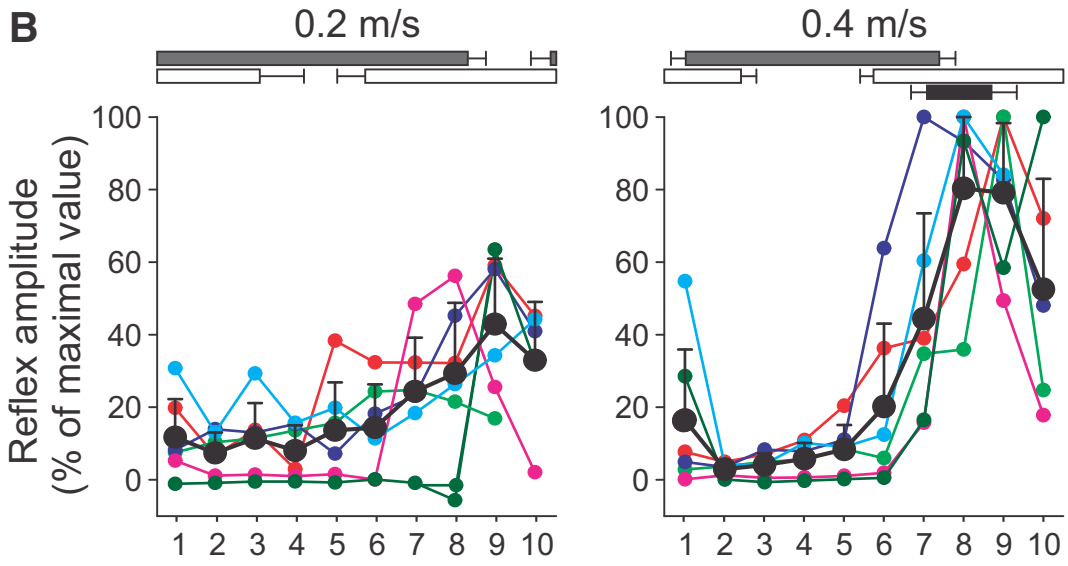

$\square$ Ipsi stance

$\square$ Contra stance

- Muscle activity

- Cat 1 - left

-C Cat 1 - right

-C Cat 2 - left

-C Cat 2 - right

- Cat 3 - left

- Cat 4 - right

$\longrightarrow$ Mean
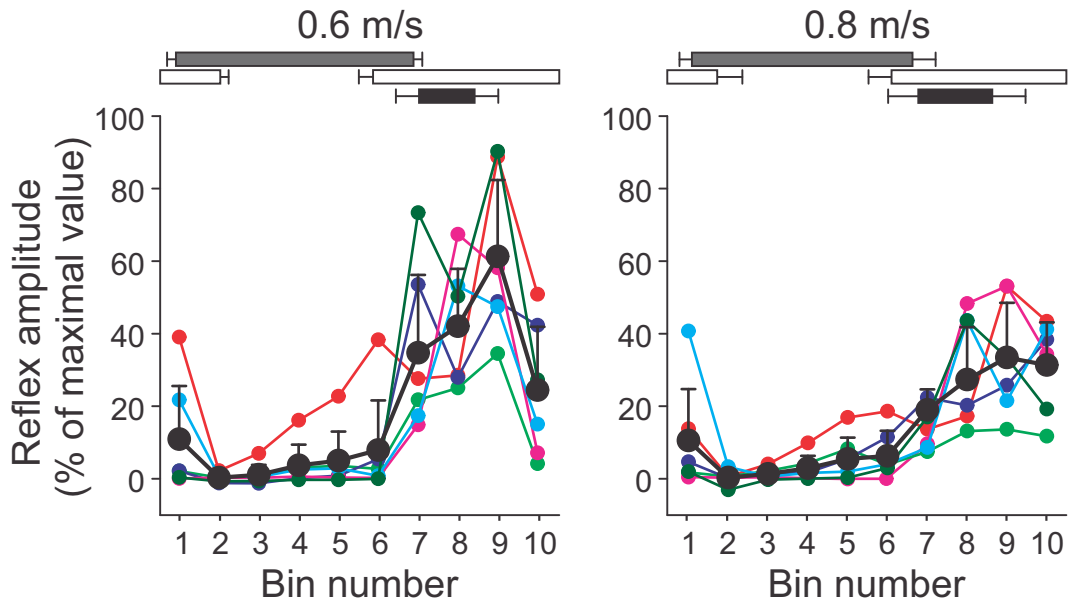

Figure 3. Phase-and speed-dependent modulation of cutaneous reflexes in the ipsilateral semitendinosus across speeds. $A$, Cutaneous reflexes evoked in a spinal cat (Cat 1 ) at 0.4 and $0.8 \mathrm{~m} / \mathrm{s}$ and separated into 10 bins. The blue lines are the rectified EMG waveforms obtained with stimulation (average of 5-17 cycles per bin). The dashed lines show the background level of EMG (average of $>90$ control cycles). The EMG waveform shown vertically on the right of each panel is the rectified activity of the muscle at each speed (average of $>90$ control cycles). $\boldsymbol{B}, \mathrm{P} 1 \mathrm{responses}$ were averaged in each bin and expressed as a percentage of the maximal value obtained at $0.4 \mathrm{~m} / \mathrm{s}$. Data are shown for individual nerve stimulations (mean) and for pooled data (mean \pm SD). The horizontal bars above the panels show the stance phases for the ipsilateral (Ipsi) and contralateral (Contra) hindlimbs, along with the period of activity of the ipsilateral semitendinosus obtained from 30 cycles. Error bars indicate mean \pm SD. $\ln \boldsymbol{A}$ and $\boldsymbol{B}$, the locomotor cycle was synchronized to onset of the ipsilateral VL. 


\section{Ipsilateral Vastus Lateralis}

A

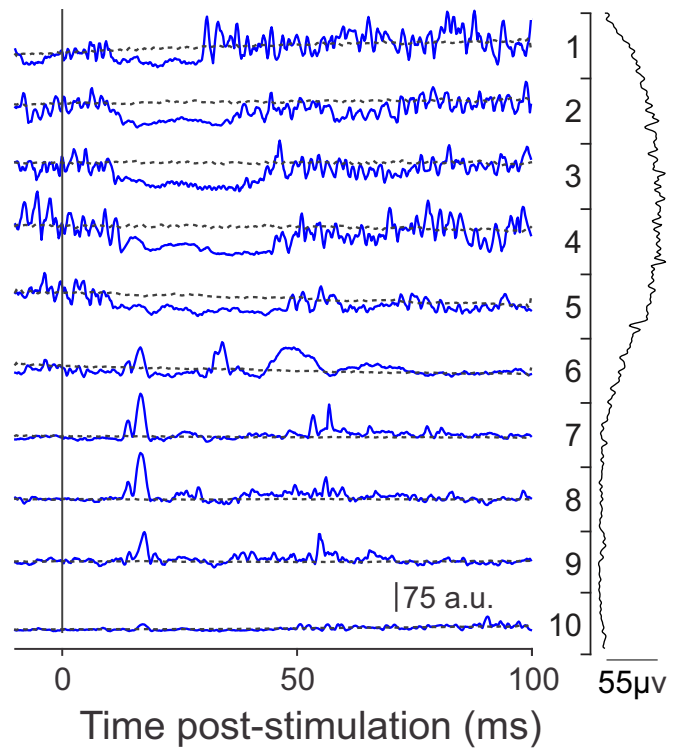

$0.8 \mathrm{~m} / \mathrm{s}$

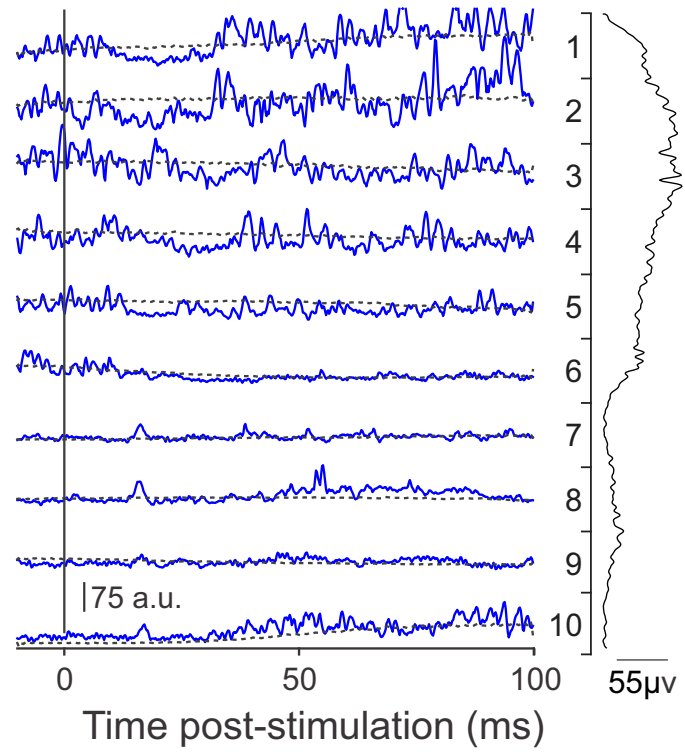

B
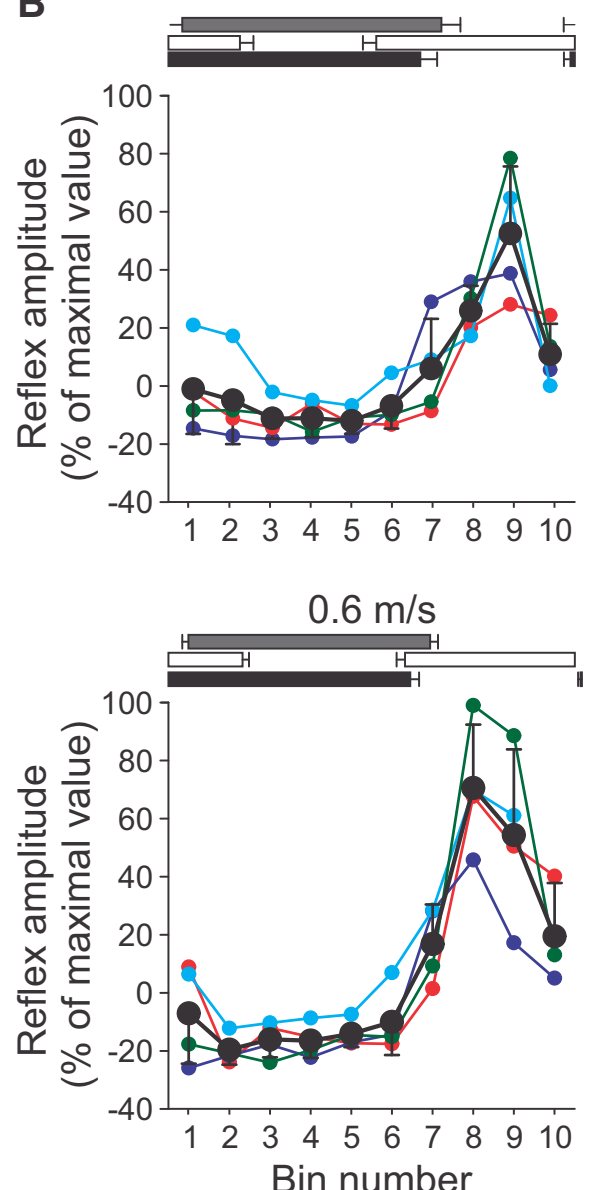

$0.4 \mathrm{~m} / \mathrm{s}$

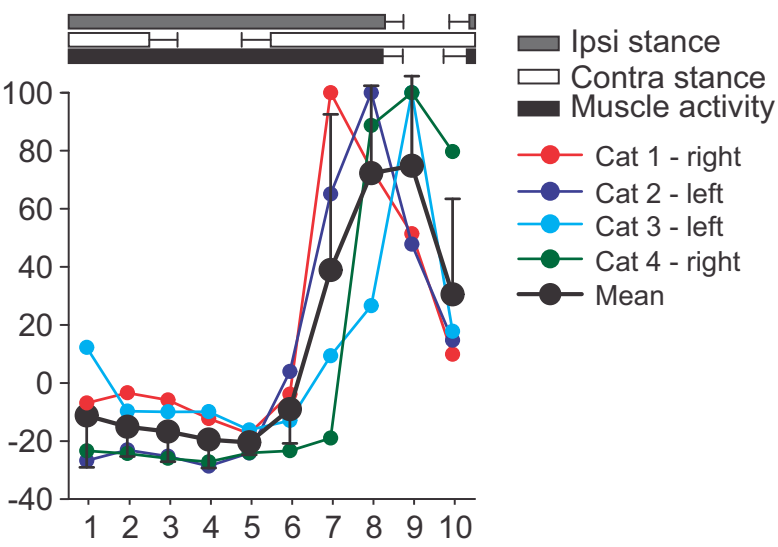

$0.8 \mathrm{~m} / \mathrm{s}$

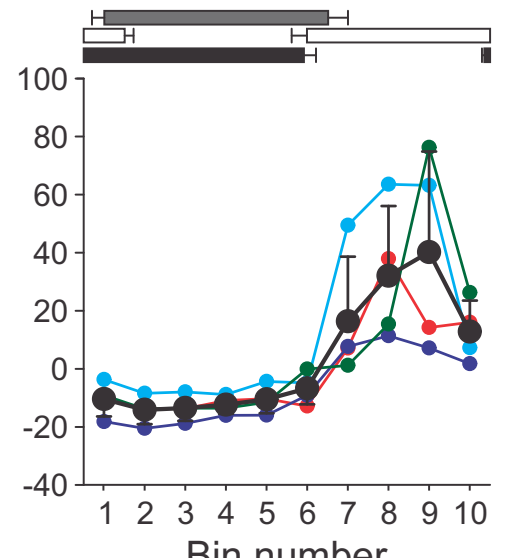

Figure 4. Phase-and speed-dependent modulation of cutaneous reflexes in the ipsilateral VL across speeds. $A$, Cutaneous reflexes evoked in a spinal cat (Cat 2) at 0.4 and $0.8 \mathrm{~m} / \mathrm{s}$ and separated into 10 bins. The blue lines are the rectified EMG waveforms obtained with stimulation (average of 5-17 cycles per bin). The dashed lines show the background level of EMG (average of $>130$ control cycles). The EMG waveform shown vertically on the right of each panel is the rectified activity of the muscle at each speed (average of $>130$ control cycles). $\boldsymbol{B}, \mathrm{P} 1$ or N1 responses were averaged in each bin and expressed as a percentage of the maximal value obtained at $0.4 \mathrm{~m} / \mathrm{s}$. Data are shown for individual nerve stimulations (mean) and for pooled data (mean $\pm S D$ ). The horizontal bars above the panels show the stance phases for the ipsilateral (Ipsi) and contralateral (Contra) hindlimbs along with the period of activity of the ipsilateral VL obtained from 30 cycles. Error bars indicate mean \pm SD. $\ln \boldsymbol{A}$ and $\boldsymbol{B}$, the locomotor cycle was synchronized to onset of the ipsilateral VL. 


\section{Ipsilateral Lateral Gastrocnemius}
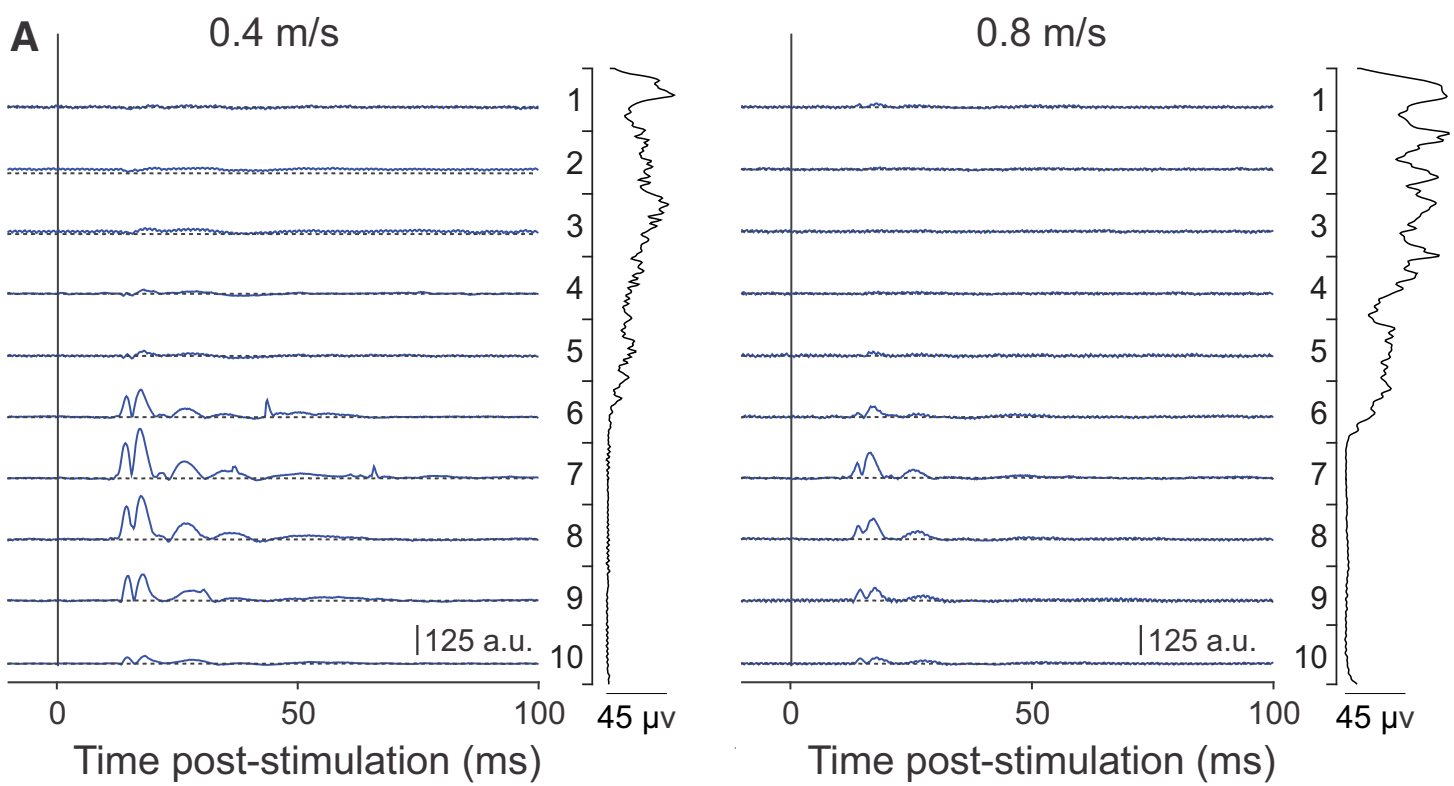

B

$0.2 \mathrm{~m} / \mathrm{s}$
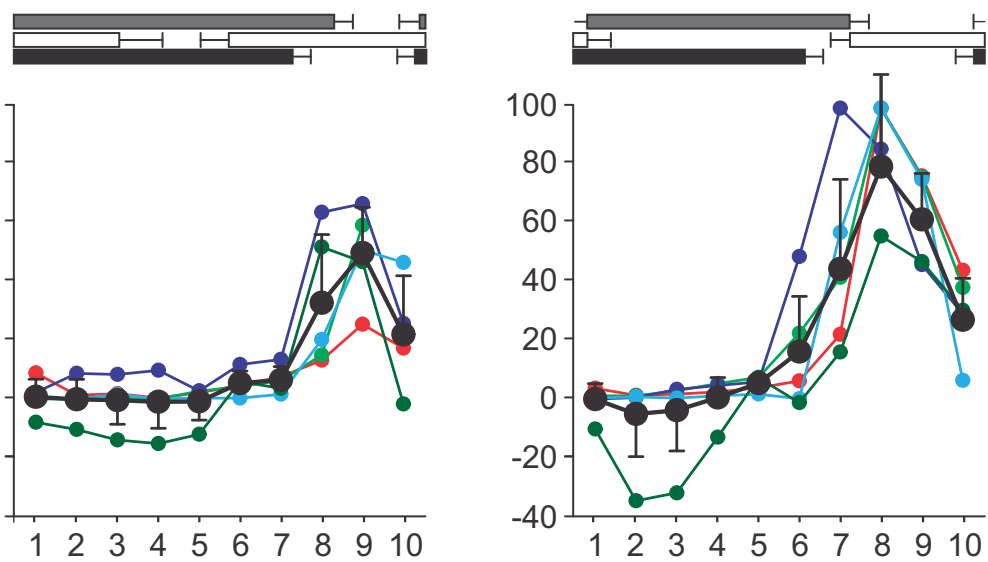

$\square$ Ipsi stance

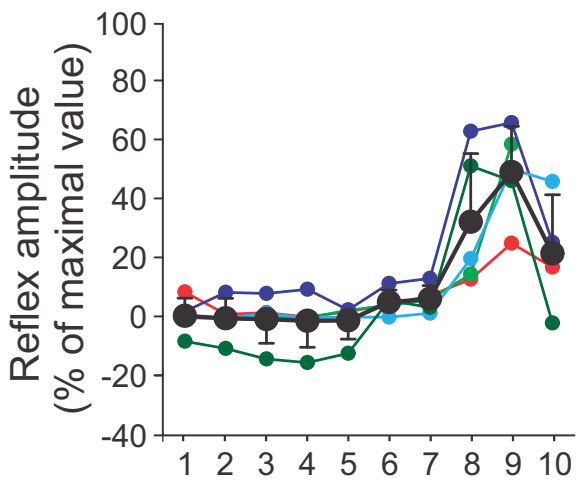

Muscle activity

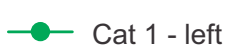

- Cat 1 - right

$\rightarrow$ Cat 2 - left

- Cat 3 - left

- Cat 4 - right

$\rightarrow$ Mean

$0.6 \mathrm{~m} / \mathrm{s}$
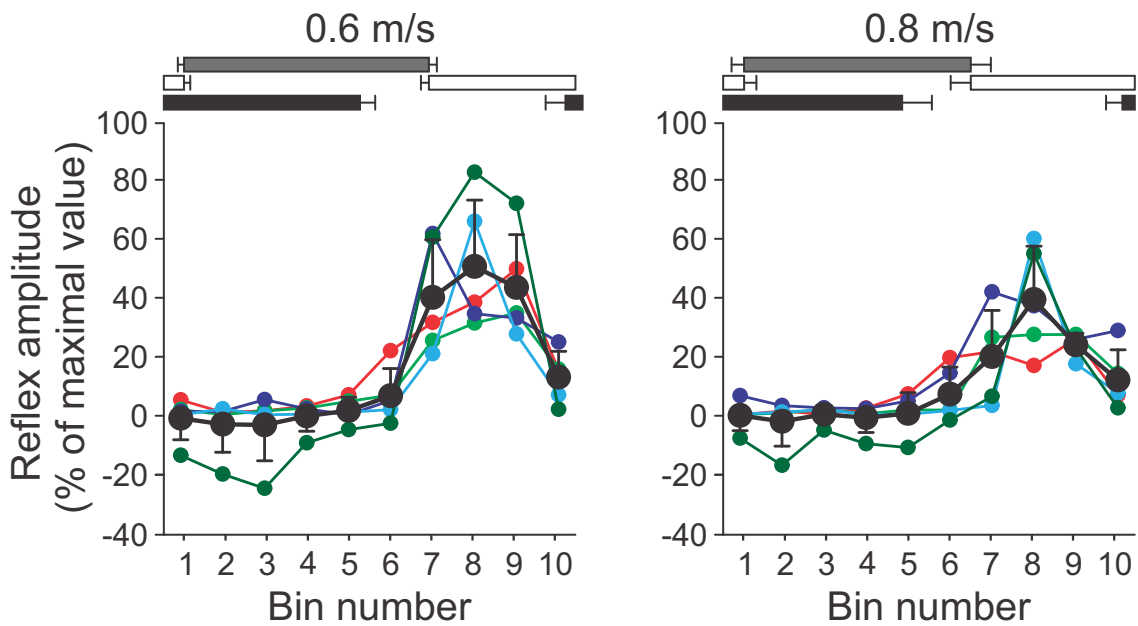

Figure 5. Phase-and speed-dependent modulation of cutaneous reflexes in the ipsilateral lateral gastrocnemius across speeds. $\boldsymbol{A}$, Cutaneous reflexes evoked in a spinal cat (Cat 2 ) at 0.4 and 0.8 $\mathrm{m} / \mathrm{s}$ and separated into 10 bins. The blue lines are the rectified EMG waveforms obtained with stimulation (average of $8-17$ cycles per bin). The dashed lines show the background level of EMG (average of $>130$ control cycles). The EMG waveform shown vertically on the right of each panel is the rectified activity of the muscle at each speed (average of $>130$ control cycles). $\boldsymbol{B}, \mathrm{P} 1$ or $\mathrm{N} 1$ responses were averaged in each bin and expressed as a percentage of the maximal value obtained at $0.4 \mathrm{~m} / \mathrm{s}$. Data are shown for individual nerve stimulations (mean) and for pooled data (mean \pm SD). The horizontal bars above the panels show the stance phases for the ipsilateral (Ipsi) and contralateral (Contra) hindlimbs, along with the period of activity of the ipsilateral lateral gastrocnemius obtained from 30 cycles. Error bars indicate mean \pm SD. In $\boldsymbol{A}$ and $\boldsymbol{B}$, the locomotor cycle was synchronized to onset of the ipsilateral VL. 
tude of $\mathrm{P} 1$ responses across the locomotor cycle (10 bins) for individual cats and for pooled data (average of nerve stimulations). In some cats, both the left and right SP evoked robust reflex responses and recordings from the muscle of interest were available. Therefore, responses evoked by both nerves are shown and treated separately. At the top of each panel are the normalized stance phases for the ipsilateral and contralateral limbs and the period of activity of the muscle where reflex responses were evoked.

To investigate the phase-and speed-dependent modulation of cutaneous reflexes in a flexor muscle, responses were evoked and recorded in the ipsilateral St muscle (Fig. 3). The St muscle, a knee flexor/hip extensor, has a brief burst of activity around the beginning of the swing phase and increased activity in this muscle by cutaneous inputs would facilitate knee flexion while moving the hip backwards. Short-latency excitatory P1 responses were obtained from 6 nerve stimulations in 4 cats at latencies of $8-10 \mathrm{~ms}$. These P1 responses were modulated with the phase of the locomotor cycle, with prominent responses present during the period of activity and throughout swing, whereas they were generally suppressed during the stance phase (Fig. 3A). This is consistent with previous findings in intact and spinal cats (Forssberg et al., 1977; Forssberg, 1979; Duysens and Loeb, 1980; Pratt et al., 1991; Loeb, 1993; Frigon and Rossignol, 2007, 2008a). The pattern of phase-dependent modulation was similar at 0.4 and $0.8 \mathrm{~m} / \mathrm{s}$, albeit with smaller responses at the faster speed. In Figure $3 B, P 1$ responses were normalized to the maximal response evoked at 0.4 $\mathrm{m} / \mathrm{s}$, which was observed in bins $7-10$, corresponding to the ipsilateral stance-to-swing transition and swing phase. Although the pattern of phase-dependent modulation was similar across speeds, P1 responses evoked during the swing phase were largest at the intermediate speeds of 0.4 and $0.6 \mathrm{~m} / \mathrm{s}$, followed by the slowest and fastest speeds of 0.2 and $0.8 \mathrm{~m} / \mathrm{s}$, respectively.

To investigate the phase-and speed-dependent modulation of cutaneous reflexes in an extensor muscle, responses were evoked and recorded in the ipsilateral VL muscle (Fig. 4). The VL muscle, a knee extensor, is active throughout the majority of the stance phase. The raw traces shown in Figure $4 A$ are representative of the reflex responses observed with four nerve stimulations in four cats. When the VL was active, stimulating the SP nerve produced a short-latency inhibition, or N1 response, at latencies of 10-14 ms. This short-latency inhibition was previously reported in intact and spinal cats (Duysens and Loeb, 1980; Abraham et al., 1985; Pratt et al., 1991; Loeb, 1993; Frigon and Rossignol, 2008a). In intact cats, the $\mathrm{N} 1$ response is generally followed by a longerlatency excitatory response termed a $\mathrm{P} 2$ or P3 response (Duysens and Loeb, 1980), whereas, in spinal cats, this longer-latency response is generally reduced (Frigon and Rossignol, 2008a). At the end of the VL burst and in its inactive phase, short-latency excitatory, or P1 responses, were found at latencies of 8-12 ms. There was a prominent effect of speed on the $\mathrm{N} 1$ and $\mathrm{P} 1$ responses in the ipsilateral VL. At $0.8 \mathrm{~m} / \mathrm{s}$, the phase-dependent modulation of cutaneous reflexes was similar to $0.4 \mathrm{~m} / \mathrm{s}$. However, the shortlatency inhibition was visibly reduced in both duration and magnitude despite a similar or slightly increased EMG burst profile. Short-latency excitatory P1 responses from bins 6-9 were also visibly reduced at $0.8 \mathrm{~m} / \mathrm{s}$ compared with $0.4 \mathrm{~m} / \mathrm{s}$. For the ipsilateral VL, all maximal responses were found at a speed of $0.4 \mathrm{~m} / \mathrm{s}$ from bins 7-9 (Fig. 4B). Across cats, N1 responses were present during most of the stance phase, whereas P1 responses were present starting at the end of stance and throughout the swing phase depending on the speed. Similar to the ipsilateral St, P1 response amplitudes were largest at $0.4 \mathrm{~m} / \mathrm{s}$, followed by $0.6 \mathrm{~m} / \mathrm{s}$ and the slowest $(0.2 \mathrm{~m} / \mathrm{s})$ and fastest $(0.8 \mathrm{~m} / \mathrm{s})$ speeds. Interestingly, $\mathrm{N} 1$ responses followed a similar pattern of modulation, with greater inhibition at intermediate speeds and smaller responses at the slowest and fastest speeds.

To investigate the phase-and speed-dependent modulation of cutaneous reflexes in an extensor muscle acting at a different joint than the VL, responses were evoked and recorded in the ipsilateral LG muscle (Fig. 5). Although this muscle primarily acts to extend the ankle, it can also flex the knee. The LG muscle is active throughout most of the stance phase. In the ipsilateral LG or its close synergist, the medial gastrocnemius, of intact cats during treadmill locomotion, stimulating cutaneous or mixed nerves of the foot evokes N1 responses during the period of activity that are followed by longer-latency excitatory or P2-P3 responses (Duysens and Loeb, 1980; Abraham et al., 1985; Loeb, 1993; Frigon and Rossignol, 2008c; Frigon et al., 2009). In the inactive period, some studies have reported short-latency excitatory, or P1, responses in intact cats (Frigon et al., 2009). In spinal cats, N1 responses are generally reduced or absent and can be replaced by $\mathrm{P} 1$ responses, depending on the cat, and $\mathrm{P} 1$ responses are observed in the inactive phase (Frigon and Rossignol, 2008a). All 5 nerve stimulations in 4 cats evoked P1 responses starting toward the end of the burst and throughout its inactive phase at latencies of 8-10 ms. In one cat (Cat 1), N1 responses were observed during the LG burst, but only on one side. Indeed, stimulating the left SP nerve produced N1 responses in the left LG, whereas stimulating the right $\mathrm{SP}$ nerve did not evoke $\mathrm{N} 1$ responses in the right LG. In the example shown, P1 responses were visibly reduced from 0.4 to $0.8 \mathrm{~m} / \mathrm{s}$. Across cats and nerve stimulations, all maximal P1 responses were found at a speed of $0.4 \mathrm{~m} / \mathrm{s}$ from bins $7-9$ (Fig. $5 B$ ). In addition, in Cat 1 with left SP nerve stimulation, N1 responses were also largest at 0.4 and $0.6 \mathrm{~m} / \mathrm{s}$ and smaller at 0.2 and $0.8 \mathrm{~m} / \mathrm{s}$. Similar to the other two ipsilateral muscles studied (St and VL), the phase-dependent modulation of $\mathrm{P} 1$ responses in LG was maintained across speeds, with smaller or absent P1 responses during the stance phase that peaked during the swing phase.

In summary, the phase-dependent modulation of shortlatency excitatory (P1) or inhibitory (N1) responses was maintained across speeds in the three ipsilateral muscles studied. The $\mathrm{P} 1$ and N1 responses were modulated nonlinearly with an increase in speed, with the largest responses observed at intermediate speeds $(0.4 \mathrm{~m} / \mathrm{s}$ followed by $0.6 \mathrm{~m} / \mathrm{s})$ and the smallest responses observed at the slowest $(0.2 \mathrm{~m} / \mathrm{s})$ and fastest $(0.8 \mathrm{~m} / \mathrm{s})$ speeds.

\section{Modulation of contralateral responses with speed}

Responses evoked in the contralateral limb, or crossed reflexes, were originally introduced as $\mathrm{P} 2$ responses in intact cats by Duysens and Loeb (1980) because they had latencies and a phase-dependent modulation that closely resembled ipsilateral P2 responses. However, ipsilateral P2 responses are generally abolished or considerably reduced in spinal cats (Frigon and Rossignol, 2008a, 2008b), whereas contralateral responses persist or are even increased (Forssberg et al., 1977; LaBella et al., 1992; Frigon and Rossignol, 2008a). Here, we found that contralateral excitatory responses had latencies between $10-15 \mathrm{~ms}$ and, as such, were considered P1 responses (see Discussion). Figures 6, 7, and 8 show contralateral P1 responses evoked in the St, VL, and LG muscles, respectively, and are arranged in the same way as Figures 3, 4, and 5.

To investigate the phase-and speed-dependent modulation of cutaneous reflexes in a flexor muscle contralateral to the stimulated limb, responses were evoked and recorded in the contralat- 


\section{Contralateral Semitendinosus}
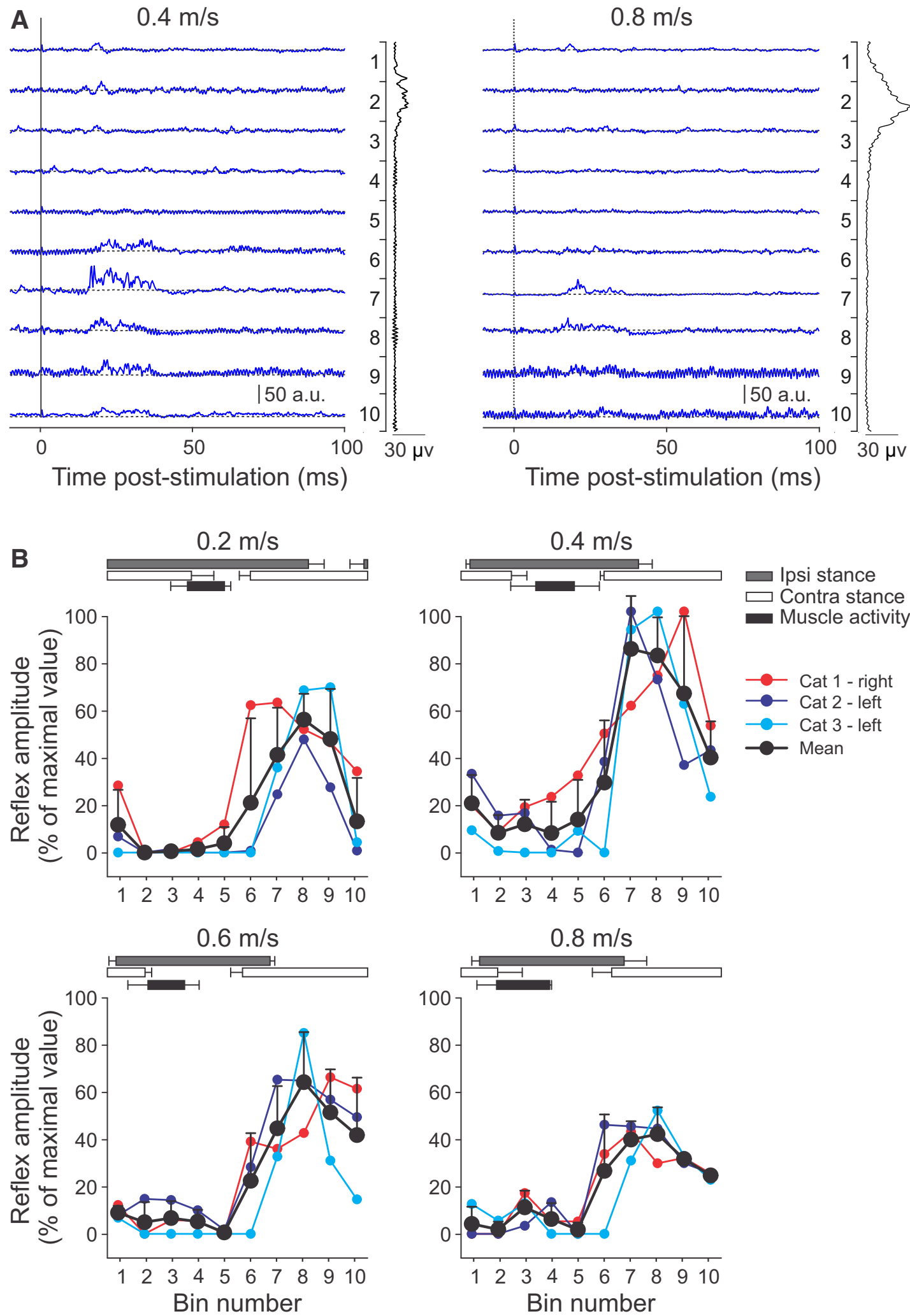

Figure 6. Phase-and speed-dependent modulation of cutaneous reflexes in the contralateral semitendinosus across speeds. $\boldsymbol{A}$, Cutaneous reflexes evoked in a spinal cat (Cat 2) at 0.4 and $0.8 \mathrm{~m} / \mathrm{s}$ and separated into 10 bins. The blue lines are the rectified EMG waveforms obtained with stimulation (average of $5-20$ cycles per bin). The dashed lines show the background level of EMG (average of $>130$ control cycles). The EMG waveform shown vertically on the right of each panel is the rectified activity of the muscle at each speed (average of $>130$ control cycles). $\boldsymbol{B}, \mathrm{P} 1$ responses were averaged in each bin and expressed as a percentage of the maximal value obtained at $0.4 \mathrm{~m} / \mathrm{s}$. Data are shown for individual nerve stimulations (mean) and for pooled data (mean \pm SD). The horizontal bars above the panels show the stance phases for the ipsilateral (Ipsi) and contralateral (Contra) hindlimbs, along with the period of activity of the contralateral semitendinosus obtained from 30 cycles. Error bars indicate mean \pm SD. In $\boldsymbol{A}$ and $\boldsymbol{B}$, the locomotor cycle was synchronized to onset of the ipsilateral VL. 


\section{Contralateral Vastus Lateralis}
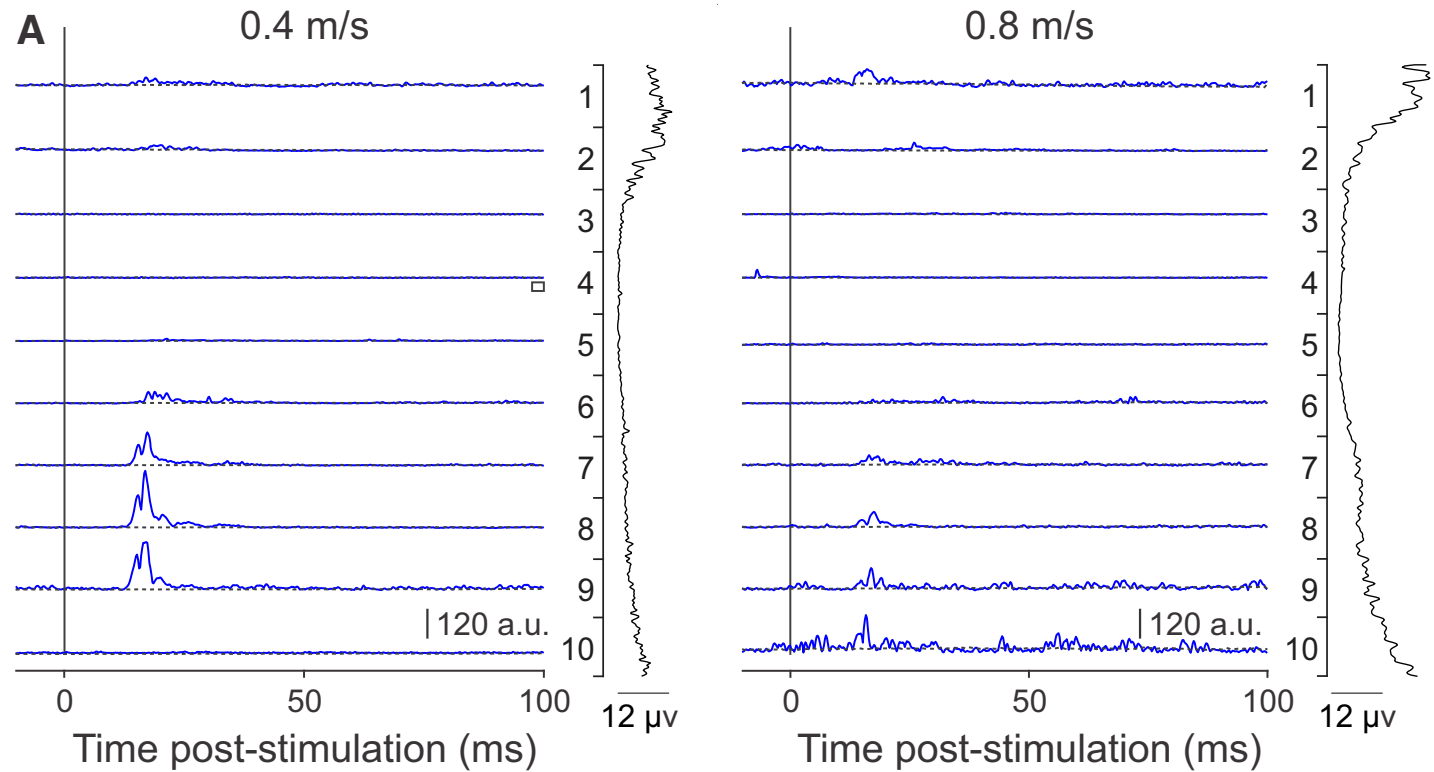

B

$0.2 \mathrm{~m} / \mathrm{s}$
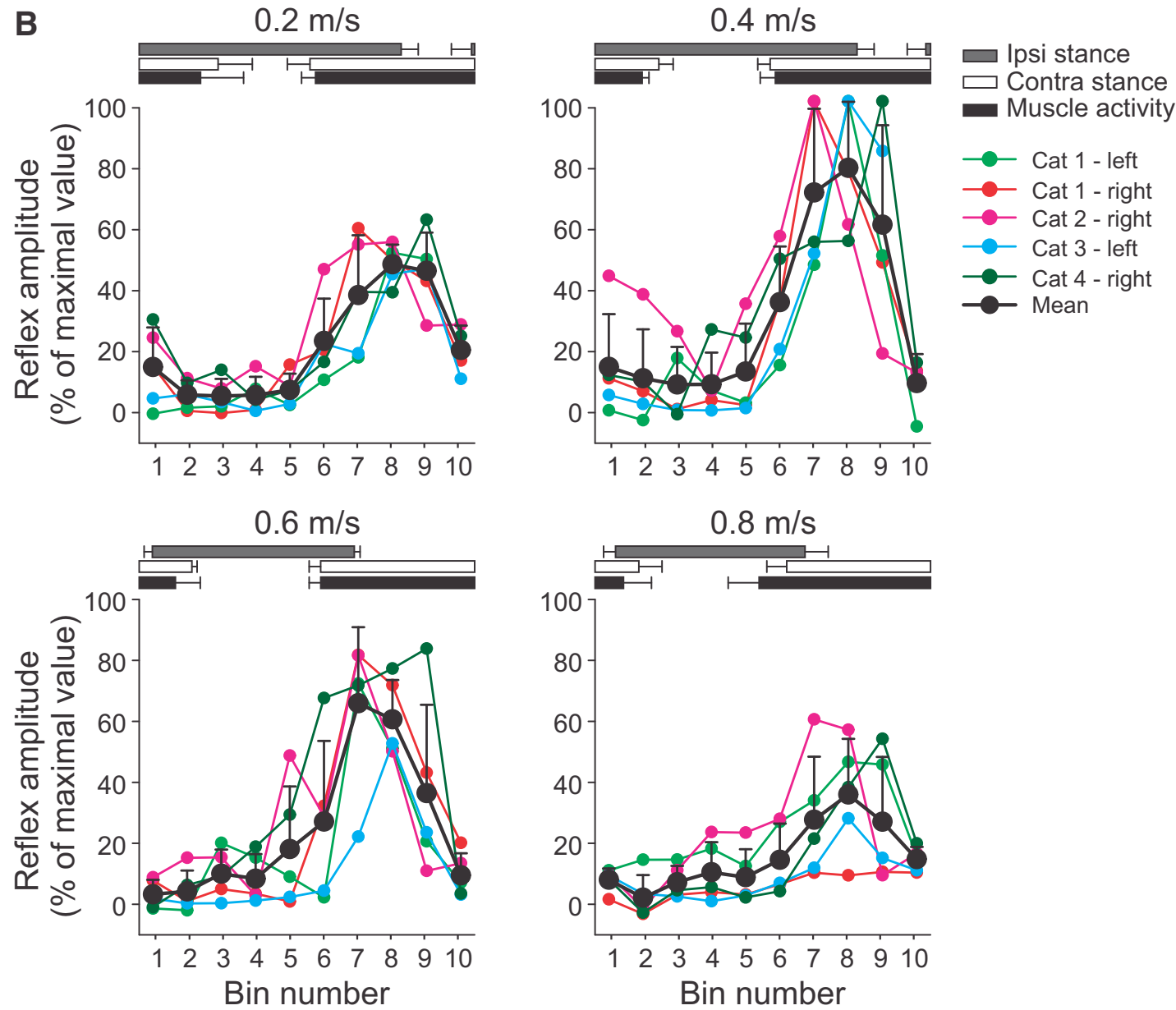

Figure 7. Phase-and speed-dependent modulation of cutaneous reflexes in the contralateral VL across speeds. $\boldsymbol{A}$, Cutaneous reflexes evoked in a spinal cat (Cat 3 ) at 0.4 and $0.8 \mathrm{~m} / \mathrm{s}$ and separated into 10 bins. The blue lines are the rectified EMG waveforms obtained with stimulation (average of $7-21$ cycles per bin). The dashed lines show the background level of EMG (average of $>60$ control cycles). The EMG waveform shown vertically on the right of each panel is the rectified activity of the muscle at each speed (average of $>60$ control cycles). $\boldsymbol{B}, \mathrm{P} 1 \mathrm{responses}$ were averaged in each bin and expressed as a percentage of the maximal value obtained at $0.4 \mathrm{~m} / \mathrm{s}$. Data are shown for individual nerve stimulations (mean) and for pooled data (mean \pm SD). The horizontal bars above the panels show the stance phases for the ipsilateral (Ipsi) and contralateral (Contra) hindlimbs, along with the period of activity of the contralateral VL obtained from 30 cycles. Error bars indicate mean \pm SD. In $\boldsymbol{A}$ and $\boldsymbol{B}$, the locomotor cycle was synchronized to onset of the ipsilateral VL. 


\section{Contralateral Lateral Gastrocnemius}
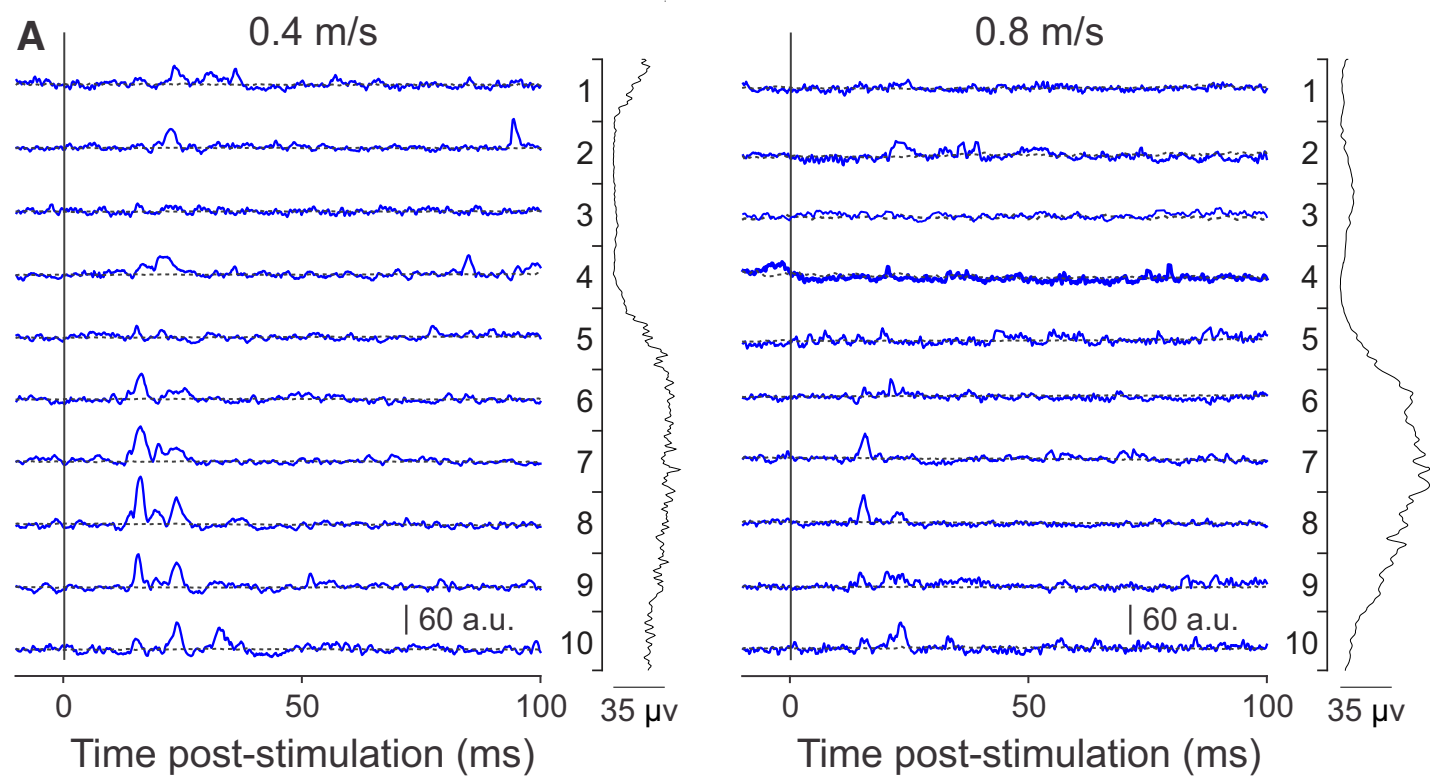

B
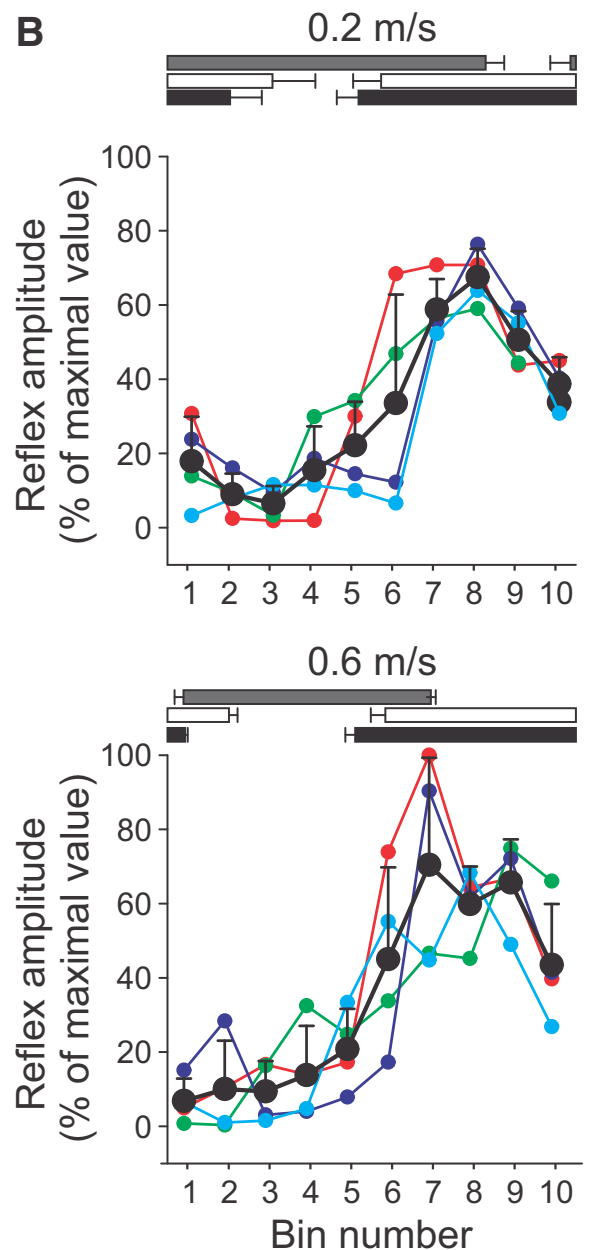
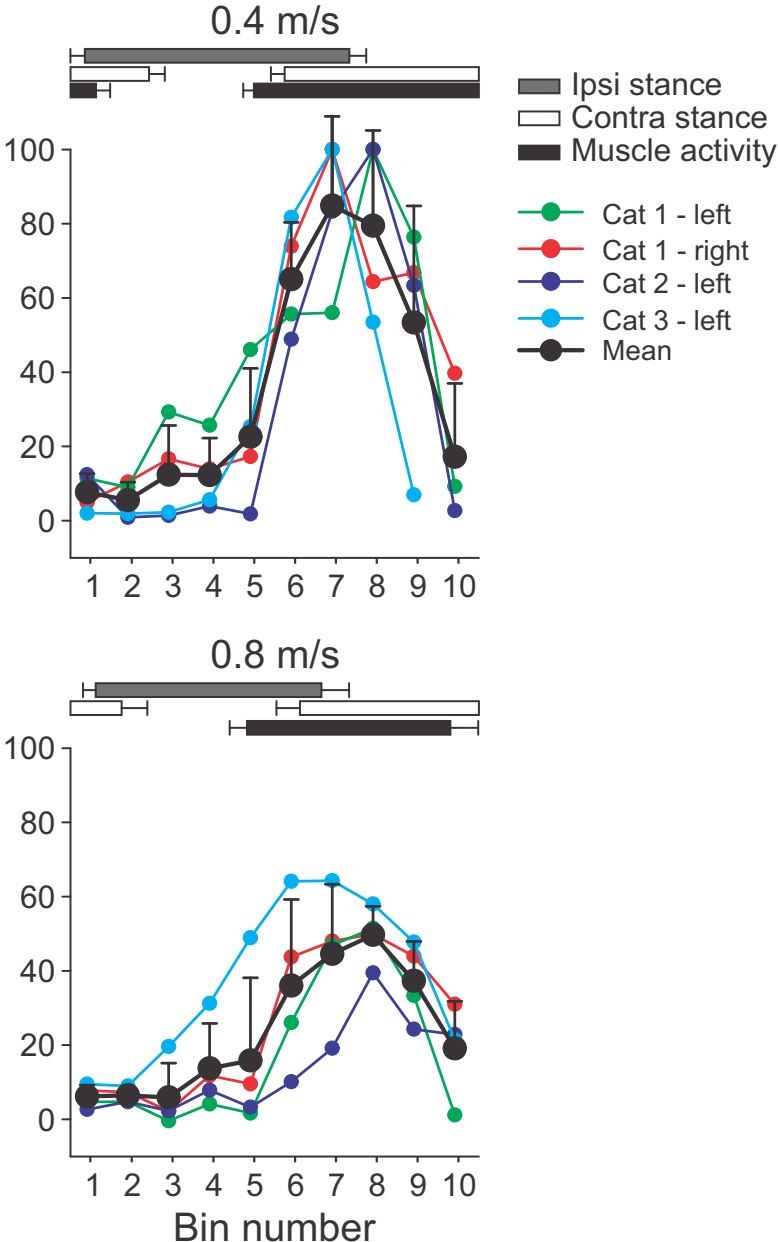

Figure 8. Phase-and speed-dependent modulation of cutaneous reflexes in the contralateral lateral gastrocnemius muscle across speeds. $\boldsymbol{A}$, Cutaneous reflexes evoked in a spinal cat (Cat 2 ) at 0.4 and $0.8 \mathrm{~m} / \mathrm{s}$ and separated into $10 \mathrm{bins}$. The blue lines are the rectified EMG waveforms obtained with stimulation (average of $4-17 \mathrm{cycles}$ per bin). The dashed lines show the background level of EMG (average of $>130$ control cycles). The EMG waveform shown vertically on the right of each panel is the rectified activity of the muscle at each speed (average of $>130$ control cycles). $\boldsymbol{B}, \mathrm{P} 1$ responses were averaged in each bin and expressed as a percentage of the maximal value obtained at $0.4 \mathrm{~m} / \mathrm{s}$. Data are shown for individual nerve stimulations (mean) and for pooled data (mean \pm SD). The horizontal bars above the panels show the stance phases for the ipsilateral (Ipsi) and contralateral (Contra) hindlimbs, along with the period of activity of the contralateral lateral gastrocnemius obtained from 30 cycles. Error bars indicate mean \pm SD. In $\boldsymbol{A}$ and $\boldsymbol{B}$, the locomotor cycle was synchronized to onset of the ipsilateral VL. 


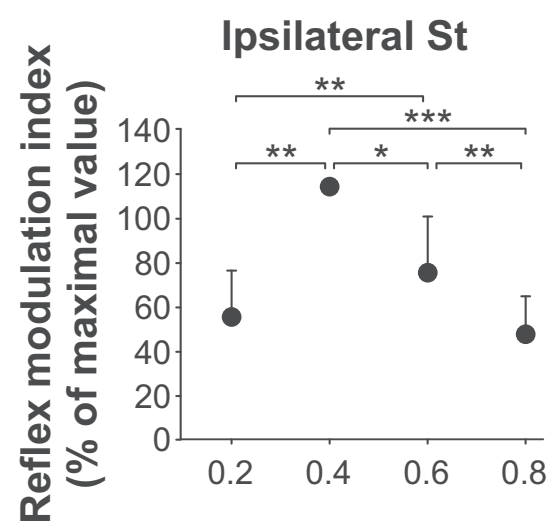

Contralateral St

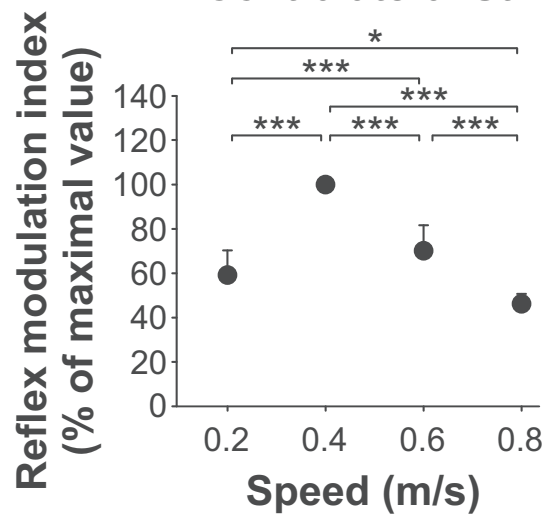

Ipsilateral VL

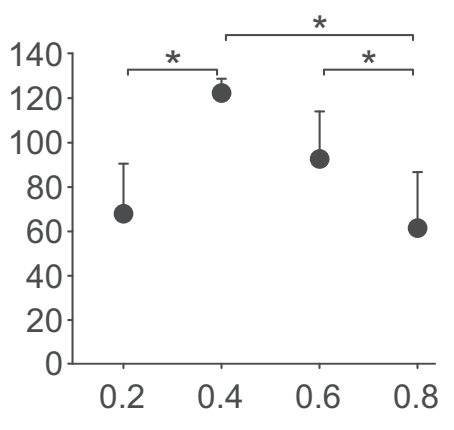

Contralateral VL

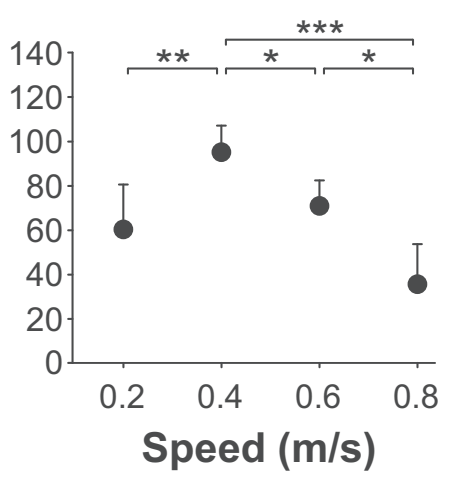

\section{Ipsilateral LG}

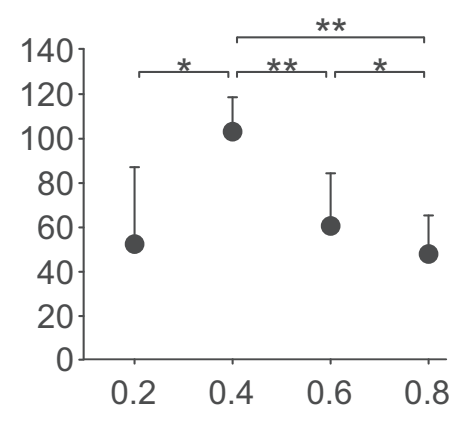

\section{Contralateral LG}

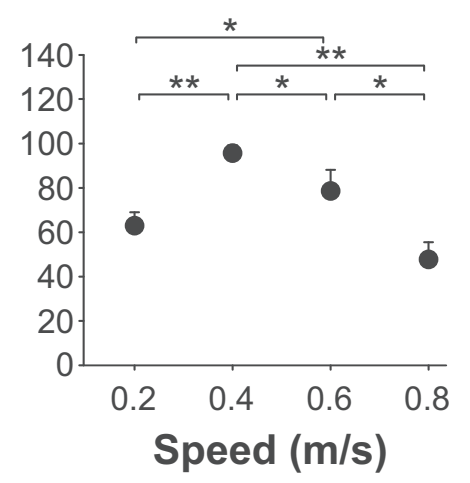

Figure 9. Modulation of cutaneous reflexes across speeds for pooled data. The modulation index was measured by subtracting the smallest response observed in one of the phases from the largest response observed in one of the other phases for all muscles and at each speed. Each bar represents the mean \pm SD of pooled data (i.e., nerves stimulated). Asterisks indicate significant differences between speeds (pairwise comparisons): ${ }^{*} p<0.05 ;{ }^{* *} p<0.01$; ${ }^{* *} p<0.001$.

eral St muscle (Fig. 6). Responses in the contralateral St were generally weak (note the scale in arbitrary units compared with other reflex responses) and were only observed with three nerve stimulations in three cats out of seven stimulated nerves in four cats. The $\mathrm{P} 1$ responses had minimal latencies of $10-15 \mathrm{~ms}$. When present, $\mathrm{P} 1$ responses in the contralateral St were largest when its limb was in stance (or when the stimulated limb was in swing) and when muscle activity was silent in bins $6-10$ (Fig. $6 \mathrm{~A}$ ). These responses were visibly reduced from 0.4 to $0.8 \mathrm{~m} / \mathrm{s}$. All maximal responses in the contralateral St were found at a speed of $0.4 \mathrm{~m} / \mathrm{s}$ from bins 7-9, when the limb was in midstance and when the stimulated limb was in swing (Fig. 6B). The phase-dependent modulation was maintained across speeds, with the largest responses observed at $0.4 \mathrm{~m} / \mathrm{s}$.

To investigate the phase-and speed-dependent modulation of cutaneous reflexes in extensor muscles contralateral to the stimulation that have biomechanical actions at different joints, responses were evoked and recorded in the contralateral VL (Fig. 7) and LG (Fig. 8) muscles. Cutaneous reflexes evoked in the contralateral VL and LG are described together because they show a similar pattern of modulation with phase and speed. All nerve stimulations showed similar patterns of responses. In contralateral VL and LG, P1 responses were observed at minimal latencies of 9-13 and 10-13 ms, respectively. P1 responses in these muscles were largest during the stance phase of its limb or when the stimulated limb was in swing and were visibly reduced from 0.4 to $0.8 \mathrm{~m} / \mathrm{s}$ (Figs. 7A, 8A). All maximal responses for the contralateral
VL and LG were found at a treadmill speed of $0.4 \mathrm{~m} / \mathrm{s}$, in bins 7-9 during midstance of the limb or the swing phase of the stimulated limb (Figs. $7 B, 8 B$ ). Similar to the contralateral St, the phasedependent modulation of $\mathrm{P} 1$ responses evoked in the contralateral VL and LG was maintained across speeds, with the largest responses observed at $0.4 \mathrm{~m} / \mathrm{s}$.

In summary, short-latency excitatory reflexes, or P1 responses, in muscles contralateral to the stimulation were: (1) largest when the limb was in midstance or when the stimulated limb was in swing, (2) maintained a similar phase-dependent modulation across speeds, and (3) modulated nonlinearly with speed, with the largest responses observed at intermediate speeds $(0.4 \mathrm{~m} / \mathrm{s}$ followed by 0.6 $\mathrm{m} / \mathrm{s})$ and the smallest responses observed at the slowest $(0.2 \mathrm{~m} / \mathrm{s})$ and fastest $(0.8 \mathrm{~m} / \mathrm{s})$ speeds.

\section{Modulation of cutaneous reflexes across speeds}

To quantify changes in cutaneous reflex amplitude across speeds, a reflex modulation index was measured at each speed by subtracting the smallest response observed in one of the phases from the largest response observed in one of the other phases for all muscles. As an example, if the largest and smallest responses found at $0.2 \mathrm{~m} / \mathrm{s}$ were observed in bins 9 and 2, respectively, and were $45 \%$ and $15 \%$ of the maximal response obtained at $0.4 \mathrm{~m} / \mathrm{s}$, then this would give a modulation index of $30 \%$ at this speed. As can be seen in Figure 9, the reflex modulation index for all muscles showed a similar profile with a change in speed, with the largest index at $0.4 \mathrm{~m} / \mathrm{s}$, followed by $0.6,0.2$, and $0.8 \mathrm{~m} / \mathrm{s}$, con- 

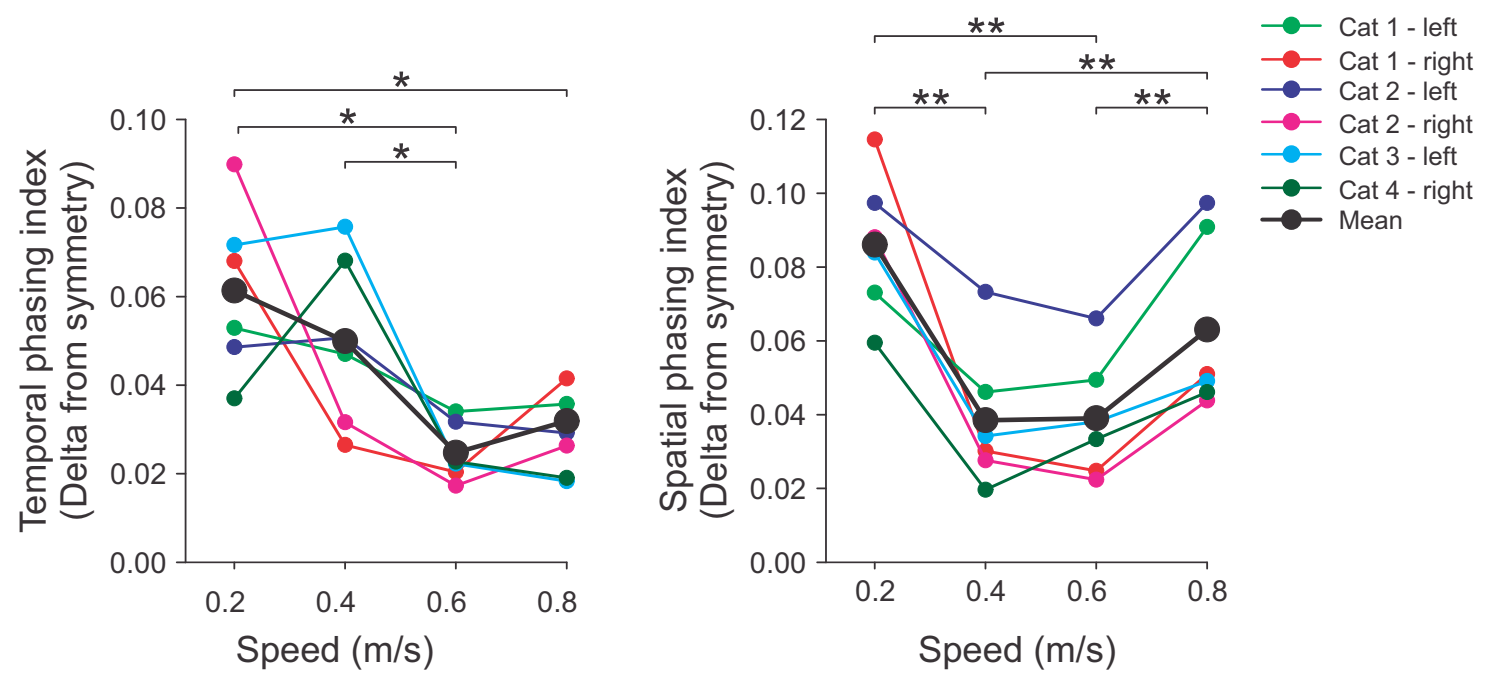

Figure 10. Temporal and spatial symmetry of the locomotor pattern across speeds. Temporal and spatial phasing intervals were measured. The deviation from a perfect symmetry of 0.5 was then calculated at each speed. Data are shown for individual cats (each data point is the average of 30 cycles) and for pooled data (i.e., six sessions from four cats). Asterisks indicate significant differences between speeds (pairwise comparisons): * $p<0.05$; ${ }^{* *} p<0.01$; ${ }^{* * *} p<0.001$.

firming that short-latency responses evoked by stimulating the SP nerve are modulated nonlinearly with increasing speed.

\section{Symmetry and step-by-step variability}

To determine whether the speed-dependent modulation of cutaneous reflexes could be tied to a functional parameter, we measured a temporal (Fig. 10A) and a spatial (Fig. 10B) phasing index, a reflection of how the locomotor pattern approaches perfect left-right symmetry. This was done for all nerve stimulations so that Cats 1 and 2 have two nerves stimulated each in the pooled data. Values closer to 0 represent a more symmetrical pattern between the left and right hindlimbs. With increasing speed, the temporal pattern showed a tendency to become more symmetrical (Fig. 10A), as shown recently in intact cats (Frigon et al., 2014) and spinal cats (Dambreville et al., 2015). Conversely, the spatial phasing index was largest at 0.2 and $0.8 \mathrm{~m} / \mathrm{s}$ and smallest at 0.4 and $0.6 \mathrm{~m} / \mathrm{s} \mathrm{(Fig.} \mathrm{10B),} \mathrm{indicating} \mathrm{that} \mathrm{the} \mathrm{hindlimb} \mathrm{locomotor}$ pattern is more spatially symmetrical at intermediate speeds. Therefore, the pattern of modulation of the spatial phasing index was similar to the speed-dependent modulation of short-latency cutaneous reflexes (Fig. 9). To assess the strength of the relationship between the temporal/spatial phasing indices and the reflex modulation index, we measured Pearson's correlation coefficient $(r)$. The temporal index showed no significant correlation $(p>$ 0.05 ) with any reflex modulation indices ( $r$ values between -0.04 and 0.21$)$. However, the spatial phasing index was significantly correlated $(p<0.01)$ with reflex modulation indices of ipsilateral muscles, with $r$ values of $-0.57,-0.70$, and -0.59 for the ipsilateral St, VL, and LG muscles, respectively. Correlation coefficients for contralateral muscles were slightly smaller, with $r$ values of $-0.40,-0.42$, and -0.49 for the contralateral St, VL, and LG, respectively, and were significant $(p<0.05)$ for VL and LG only. Therefore, the modulation of short-latency cutaneous reflexes with speed correlates with the spatial symmetry of the left and right hindlimbs.

\section{Discussion}

\section{Phase-and speed-dependent modulation of} cutaneous reflexes

To be functionally appropriate, cutaneous feedback is modulated with the phase of the cycle (Zehr and Stein, 1999; Duysens et al., 2004b; Rossignol et al., 2006). Previous studies have shown that short-latency excitatory, or P1, responses in St and its functional synergists (e.g., semimembranosus, posterior biceps femoris) evoked by stimulating cutaneous (SP, sural or saphenous) or mixed (tibial) nerves were modulated with phase during treadmill locomotion in intact and spinal cats, peaking during swing and being reduced or absent during stance (Forssberg et al., 1977; Forssberg, 1979; Duysens and Loeb, 1980; Pratt et al., 1991; Loeb, 1993; Frigon and Rossignol, 2007, 2008a). It is important to consider that some of the observed responses and their modulation could be due to changes within the spinal cord induced by the transection and/or the loss of supraspinal inputs. For example, in intact cats, stimulating cutaneous or mixed nerves of the foot evoked N1 responses in ipsilateral extensors during their period of activity (Duysens and Loeb, 1980; Abraham et al., 1985; Pratt et al., 1991; Frigon and Rossignol, 2007, 2008c; Frigon et al., 2009), which were generally reduced after spinal transection and could even be replaced by P1 responses (Frigon and Rossignol, 2008a). The present results agree with those of Frigon and Rossignol (2008a) finding a mixture of P1 and N1 responses in ipsilateral LG and a maintenance of $\mathrm{N} 1$ responses in ipsilateral VL during their period of activity after spinal transection. Overall, $\mathrm{P} 1$ and $\mathrm{N} 1$ responses evoked in spinal cats resemble those observed in intact cats. The similar phase-dependent modulation of short-latency excitatory and inhibitory responses in intact and spinal cats, as well as in humans, indicates that they are primarily mediated and modulated at a spinal level, which does not preclude a supraspinal contribution.

The most novel finding of the present study was the nonlinear modulation of $\mathrm{P} 1$ and $\mathrm{N} 1$ response amplitudes with increasing speed in all recorded muscles ipsilateral and contralateral to the stimulation. The largest excitatory and inhibitory responses were observed at the intermediate speeds of 0.4 and $0.6 \mathrm{~m} / \mathrm{s}$ and the smallest responses were found at the slowest and fastest speeds of 0.2 and $0.8 \mathrm{~m} / \mathrm{s}$, respectively. Importantly, the pattern of phasedependent modulation was maintained across speeds, with P1 responses peaking during the swing phase. Baken et al. (2005) also showed that phase-dependent modulation of suppressive responses in biceps femoris was conserved at treadmill speeds of 4.0 and $6.0 \mathrm{~km} / \mathrm{h}$ in one human subject. In intact cats, shortlatency cutaneous reflexes in the anterior biceps femoris are also 
suppressive (i.e., N1 responses) during its period of activity (Pratt et al., 1991).

The SP nerve supplies the skin of the foot/hindpaw dorsum and helps correct limb trajectory when contacting an obstacle. From a functional perspective, why would it be useful to modulate cutaneous reflexes when changing locomotor speed? Previous studies have suggested that reducing reflex amplitude with increasing speed could help prevent saturation of the motor pool (Capaday and Stein, 1987; Edamura et al., 1991). Although this could be a factor, changes in cutaneous reflex amplitude did not follow changes in background EMG activity. The short-latency inhibitory response observed in VL is an example. Despite larger background EMG activity at $0.8 \mathrm{~m} / \mathrm{s}$, there was less ongoing inhibition of the extensor burst during its period of activity compared with $0.4 \mathrm{~m} / \mathrm{s}$ (Fig. 4). A more likely function of reducing cutaneous reflexes at some speeds is to prevent cutaneous inputs from perturbing or destabilizing the pattern. Although we can only speculate, the spinal locomotor central pattern generator (CPG) might reduce the effect of somatosensory inputs when it considers that the pattern is unstable. Spinal circuits could compare somatosensory inputs from the two limbs to determine whether there is a mismatch and potential instability of the pattern. Consistent with this hypothesis, we found that spatial symmetry correlated with the modulation of cutaneous reflexes of ipsilateral and contralateral muscles, whereas the temporal symmetry was not correlated (cf. Figs. 9, 10). In other words, this suggests that the modulation of cutaneous reflexes evoked by stimulating the SP nerve is related to spatial, and not temporal, left-right coordination. Therefore, we propose that spatial cues inform the spinal locomotor network, which in turn reduces the amplitude of cutaneous reflexes at certain speeds to maximize dynamic stability.

\section{Contralateral $\mathrm{P} 1$ or $\mathrm{P} 2$ responses?}

In introducing the nomenclature for cutaneous reflex responses, Duysens and Loeb (1980) identified contralateral responses as P2 because they shared similarities with ipsilateral P2 responses in terms of latency and phase modulation. Here, we referred to contralateral responses as $\mathrm{P} 1$ because they closely resembled ipsilateral P1 responses. Ipsilateral P2 responses are known to be considerably reduced or absent after spinal transection in cats (Frigon and Rossignol, 2008a, 2008b) or in pathological conditions that reduce supraspinal drive in humans (Jones and Yang, 1994; Zehr et al., 1998; Duysens et al., 2004a; Duysens et al., 2004b), suggesting that ipsilateral P2 responses require a supraspinal contribution. However, contralateral responses are still present after spinal transection in cats (Forssberg et al., 1977; LaBella et al., 1992; Frigon and Rossignol, 2008a) and, as shown here, they show similar speed-dependent modulation as ipsilateral P1 responses. In addition, Duysens and Loeb (1980) identified the latency of their contralateral responses at $20-25 \mathrm{~ms}$ based on the interval from stimulation onset to the peak of activity. In spinal cats, using the rising phase of the response as the onset, Forssberg et al. (1977) reported contralateral responses in the quadriceps at $\sim 12 \mathrm{~ms}$ after stimulation onset (see their Fig. 6), as did LaBella et al. (1992) in St at a latency of 9-10 ms (see their Fig. $2 C)$. In the present study, contralateral responses had minimal latencies of $10 \mathrm{~ms}$, which is just 2-3 ms more than the earliest ipsilateral P1 responses, consistent with transmission through one or two additional spinal interneurons at segmental levels. For these reasons, we propose that contralateral responses should be considered P1 responses and, similar to their ipsilateral counterpart, they are generated and modulated primarily at a spinal level, although a supraspinal contribution is also likely. This is an important distinction that will need to be revisited in intact cats and in cats with different types of incomplete spinal lesions to help identify the structures/pathways mediating the responses occurring at different latencies in the ipsilateral and contralateral limbs.

\section{Speed-dependent cutaneous reflex modulation: mechanisms}

The simplest mechanism for the modulation of cutaneous reflexes is that reflex amplitude changes with the state of excitation of the $\alpha$-motoneuron pool. For example, an incoming afferent input will generate a larger response if a greater number of motoneurons are at or near firing threshold. This mechanism probably contributes because responses are primarily observed when the muscle is active. However several studies have shown that cutaneous reflex amplitude can be modulated independently of background EMG activity in cats and humans (Duysens and Loeb, 1980; Loeb, 1993; Baken et al., 2005; Frigon and Rossignol, 2007, 2008a; Frigon et al., 2009). In the present study, our measure of reflex amplitude accounted for changes in the background level of EMG activity (see Materials and Methods) and both short-latency excitatory and inhibitory responses were clearly modulated with phase and speed. Therefore, reflex modulation is mostly likely mediated by a combination of motoneuronal and premotoneuronal mechanisms. Premotoneuronal mechanisms can include gating of the transmission by interneurons within or outside the reflex pathway or at the primary afferent itself (e.g., via presynaptic inhibition). In zebrafish, different interneurons are recruited with increasing speed whereas those involved at slower speeds are silenced (McLean et al., 2007; McLean et al., 2008). Recent studies have also shown that different neuronal networks can be involved at slow versus fast speeds during mammalian locomotion (Talpalar and Kiehn, 2010; Vasudevan and Bastian, 2010; Talpalar et al., 2013; Bellardita and Kiehn, 2015). If a similar principle of interneuronal recruitment is present in cats with increasing speed, then incoming afferent inputs would be strongly gated by the active set of interneurons before reaching $\alpha$-motoneurons. Although we cannot confirm the type of gait pattern that our spinal cats were producing at the different speeds, which is generally done by measuring the duty cycle and the phasing between the forelimbs and hindlimbs, the slowest speed of $0.2 \mathrm{~m} / \mathrm{s}$ would mostly likely correspond to a walking gait and speeds of $0.4-0.8 \mathrm{~m} / \mathrm{s}$ would correspond to a trotting or pacing gait (Hildebrand, 1976; Hildebrand, 1989). Therefore, it is possible that cutaneous reflex amplitude was modulated linearly within a gait pattern (e.g., trot) and that the slowest speed tested of $0.2 \mathrm{~m} / \mathrm{s}$ corresponded to a different type of gait and thus a different set of active interneurons.

In conclusion, we found that short-latency excitatory or inhibitory responses evoked by inputs from the skin were modulated nonlinearly with increasing speed, a phenomenon that was generalized to muscles crossing different joints and located in different limbs. The present work highlights how the interactions that take place between spinal locomotor CPGs and somatosensory feedback from the skin are modulated when adjusting to a change in speed.

\section{References}

Abourachid A, Herbin M, Hackert R, Maes L, Martin V (2007) Experimental study of coordination patterns during unsteady locomotion in mammals. J Exp Biol 210:366-372. CrossRef Medline

Abraham LD, Marks WB, Loeb GE (1985) The distal hindlimb musculature of the cat: cutaneous reflexes during locomotion. Exp Brain Res 58:594603. CrossRef Medline 
Baken BC, Dietz V, Duysens J (2005) Phase-dependent modulation of short latency cutaneous reflexes during walking in man. Brain Res 1031:268275. CrossRef Medline

Bellardita C, Kiehn O (2015) Phenotypic characterization of speed-associated gait changes in mice reveals modular organization of locomotor networks. Curr Biol 25:1426-1436. CrossRef Medline

Bolton DA, Misiaszek JE (2009) Contribution of hindpaw cutaneous inputs to the control of lateral stability during walking in the cat. J Neurophysiol 102:1711-1724. CrossRef Medline

Bouyer LJ, Rossignol S (2003a) Contribution of cutaneous inputs from the hindpaw to the control of locomotion. I. Intact cats. J Neurophysiol 90: 3625-3639. CrossRef Medline

Bouyer LJ, Rossignol S (2003b) Contribution of cutaneous inputs from the hindpaw to the control of locomotion. II. Spinal cats. J Neurophysiol 90:3640-3653. CrossRef Medline

Capaday C, Stein RB (1987) Difference in the amplitude of the human soleus $\mathrm{H}$ reflex during walking and running. J Physiol 392:513-522. CrossRef Medline

Dambreville C, Labarre A, Thibaudier Y, Hurteau MF, Frigon A (2015) The spinal control of locomotion and step-to-step variability in left-right symmetry from slow to moderate speeds. J Neurophysiol 114:1119-1128. CrossRef Medline

Dambreville C, Charest J, Thibaudier Y, Hurteau MF, Kuczynski V, Grenier G, Frigon A (2016) Adaptive muscle plasticity of a remaining agonist following denervation of its close synergists in a model of complete spinal cord injury. J Neurophysiol 116:1366-1374. CrossRef Medline

D'Angelo G, Thibaudier Y, Telonio A, Hurteau MF, Kuczynski V, Dambreville C, Frigon A (2014) Modulation of phase durations, phase variations and temporal coordination of the four limbs during quadrupedal split-belt locomotion in intact adult cats. J Neurophysiol 112:1825-1837. CrossRef Medline

Duysens J (1977a) Fluctuations in sensitivity to rhythm resetting effects during the cat's step cycle. Brain Res 133:190-195. CrossRef Medline

Duysens J (1977b) Reflex control of locomotion as revealed by stimulation of cutaneous afferents in spontaneously walking premammillary cats. J Neurophysiol 40:737-751. Medline

Duysens J, Loeb GE (1980) Modulation of ipsi- and contralateral reflex responses in unrestrained walking cats. J Neurophysiol 44:1024-1037. Medline

Duysens J, Tax AA, van der Doelen B, Trippel M, Dietz V (1991) Selective activation of human soleus or gastrocnemius in reflex responses during walking and running. Exp Brain Res 87:193-204. CrossRef Medline

Duysens J, Clarac F, Cruse H (2000) Load-regulating mechanisms in gait and posture: comparative aspects. Physiol Rev 80:83-133. Medline

Duysens J, Baken BC, Burgers L, Plat FM, den Otter AR, Kremer HP (2004a) Cutaneous reflexes from the foot during gait in hereditary spastic paraparesis. Clin Neurophysiol 115:1057-1062. CrossRef Medline

Duysens J, Bastiaanse CM, Smits-Engelsman BC, Dietz V (2004b) Gait acts as a gate for reflexes from the foot. Can J Physiol Pharmacol 82:715-722. CrossRef Medline

Edamura M, Yang JF, Stein RB (1991) Factors that determine the magnitude and time course of human H-reflexes in locomotion. J Neurosci 11:420427. Medline

Forssberg H (1979) Stumbling corrective reaction: a phase-dependent compensatory reaction during locomotion. J Neurophysiol 42:936-953. Medline

Forssberg H, Grillner S, Rossignol S (1977) Phasic gain control of reflexes from the dorsum of the paw during spinal locomotion. Brain Res 132: 121-139. CrossRef Medline

Forssberg H, Grillner S, Halbertsma J (1980a) The locomotion of the low spinal cat. I. Coordination within a hindlimb. Acta Physiol Scand 108: 269-281. CrossRef Medline

Forssberg H, Grillner S, Halbertsma J, Rossignol S (1980b) The locomotion of the low spinal cat. II. Interlimb coordination. Acta Physiol Scand 108: 283-295. CrossRef Medline

Frigon A, Rossignol S (2007) Plasticity of reflexes from the foot during locomotion after denervating ankle extensors in intact cats. J Neurophysiol 98:2122-2132. CrossRef Medline

Frigon A, Rossignol S (2008a) Adaptive changes of the locomotor pattern and cutaneous reflexes during locomotion studied in the same cats before and after spinalization. J Physiol 586:2927-2945. CrossRef Medline

Frigon A, Rossignol S (2008b) Locomotor and reflex adaptation after partial denervation of ankle extensors in chronic spinal cats. J Neurophysiol 100:1513-1522. CrossRef Medline

Frigon A, Rossignol S (2008c) Short-latency crossed inhibitory responses in extensor muscles during locomotion in the cat. J Neurophysiol 99:989 998. CrossRef Medline

Frigon A, Rossignol S (2009) Partial denervation of ankle extensors prior to spinalization in cats impacts the expression of locomotion and the phasic modulation of reflexes. Neuroscience 158:1675-1690. CrossRef Medline

Frigon A, Carroll TJ, Jones KE, Zehr EP, Collins DF (2007) Ankle position and voluntary contraction alter maximal $\mathrm{M}$ waves in soleus and tibialis anterior. Muscle Nerve 35:756-766. CrossRef Medline

Frigon A, Barrière G, Leblond H, Rossignol S (2009) Asymmetric changes in cutaneous reflexes after a partial spinal lesion and retention following spinalization during locomotion in the cat. J Neurophysiol 102:26672680. CrossRef Medline

Frigon A, D'Angelo G, Thibaudier Y, Hurteau MF, Telonio A, Kuczynski V, Dambreville C (2014) Speed-dependent modulation of phase variations on a step-by-step basis and its impact on the consistency of interlimb coordination during quadrupedal locomotion in intact adult cats. J Neurophysiol 111:1885-1902. CrossRef Medline

Frigon A, Thibaudier Y, Hurteau MF (2015) Modulation of forelimb and hindlimb muscle activity during quadrupedal tied-belt and split-belt locomotion in intact cats. Neuroscience 290:266-278. CrossRef Medline

Frigon A, Desrochers É, Thibaudier Y, Hurteau MF, Dambreville C (2017) Left-right coordination from simple to extreme conditions during splitbelt locomotion in the chronic spinal adult cat. J Physiol 595:341-361. CrossRef Medline

Gerilovsky L, Tsvetinov P, Trenkova G (1989) Peripheral effects on the amplitude of monopolar and bipolar H-reflex potentials from the soleus muscle. Exp Brain Res 76:173-181. Medline

Goetz L, Piallat B, Thibaudier Y, Montigon O, David O, Chabardès S (2012) A non-human primate model of bipedal locomotion under restrained condition allowing gait studies and single unit brain recordings. J Neurosci Methods 204:306-317. CrossRef Medline

Grillner S, Halbertsma J, Nilsson J, Thorstensson A (1979) The adaptation to speed in human locomotion. Brain Res 165:177-182. CrossRef Medline

Guertin P, Angel MJ, Perreault MC, McCrea DA (1995) Ankle extensor group I afferents excite extensors throughout the hindlimb during fictive locomotion in the cat. J Physiol 487:197-209. CrossRef Medline

Hauglustaine S, Berger W, Duysens J (1998) Selective activation of MG in sural nerve reflexes during hopping, running and walking. Gait Posture 7:16-25. CrossRef

Hildebrand M (1976) Analysis of tetrapod gaits: general considerations and symmetrical gaits. In: Neural control of locomotion (Herman RM, Grillner S, Stein PSG, Stuart DG, eds), pp 203-236. New York: Plenum.

Hildebrand M (1989) The quadrupedal gaits of vertebrates. BioScience 39: 766-775. CrossRef

Hoogkamer W, Bruijn SM, Duysens J (2014) Stride length asymmetry in split-belt locomotion. Gait Posture 39:652-654. CrossRef Medline

Hurteau MF, Thibaudier Y, Dambreville C, Desaulniers C, Frigon A (2015) Effect of stimulating the lumbar skin caudal to a complete spinal cord injury on hindlimb locomotion. J Neurophysiol 113:669-676. CrossRef Medline

Ivanenko YP, Poppele RE, Lacquaniti F (2006) Spinal cord maps of spatiotemporal alpha-motoneuron activation in humans walking at different speeds. J Neurophysiol 95:602-618. Medline

Jones CA, Yang JF (1994) Reflex behavior during walking in incomplete spinal-cord-injured subjects. Exp Neurol 128:239-248. CrossRef Medline

LaBella LA, Niechaj A, Rossignol S (1992) Low-threshold, short-latency cutaneous reflexes during fictive locomotion in the "semi-chronic" spinal cat. Exp Brain Res 91:236-248. Medline

Loeb GE (1993) The distal hindlimb musculature of the cat: interanimal variability of locomotor activity and cutaneous reflexes. Exp Brain Res 96:125-140. Medline

Matthews PB (1986) Observations on the automatic compensation of reflex gain on varying the pre-existing level of motor discharge in man. J Physiol 374:73-90. CrossRef Medline

McLean DL, Fan J, Higashijima S, Hale ME, Fetcho JR (2007) A topographic map of recruitment in spinal cord. Nature 446:71-75. CrossRef Medline

McLean DL, Masino MA, Koh IY, Lindquist WB, Fetcho JR (2008) Contin- 
uous shifts in the active set of spinal interneurons during changes in locomotor speed. Nat Neurosci 11:1419-1429. CrossRef Medline

Nilsson J, Thorstensson A, Halbertsma J (1985) Changes in leg movements and muscle activity with speed of locomotion and mode of progression in humans. Acta Physiol Scand 123:457-475. CrossRef Medline

Pierotti DJ, Roy RR, Gregor RJ, Edgerton VR (1989) Electromyographic activity of cat hindlimb flexors and extensors during locomotion at varying speeds and inclines. Brain Res 481:57-66. CrossRef Medline

Pratt CA, Loeb GE (1991) Functionally complex muscles of the cat hindlimb. I. Patterns of activation across sartorius. Exp Brain Res 85:243-256. CrossRef Medline

Pratt CA, Chanaud CM, Loeb GE (1991) Functionally complex muscles of the cat hindlimb. IV. Intramuscular distribution of movement command signals and cutaneous reflexes in broad, bifunctional thigh muscles. Exp Brain Res 85:281-299. CrossRef Medline

Prochazka A, Sontag KH, Wand P (1978) Motor reactions to perturbations of gait: proprioceptive and somesthetic involvement. Neurosci Lett 7:3539. CrossRef Medline

Quevedo J, Stecina K, Gosgnach S, McCrea DA (2005) Stumbling corrective reaction during fictive locomotion in the cat. J Neurophysiol 94:20452052. CrossRef Medline

Rossignol S, Frigon A (2011) Recovery of locomotion after spinal cord injury: some facts and mechanisms. Annu Rev Neurosci 34:413-440. CrossRef Medline

Rossignol S, Dubuc R, Gossard JP (2006) Dynamic sensorimotor interactions in locomotion. Physiol Rev 86:89-154. CrossRef Medline

Schillings AM, Van Wezel BM, Duysens J (1996) Mechanically induced stumbling during human treadmill walking. J Neurosci Methods 67:1117. CrossRef Medline

Schomburg ED, Petersen N, Barajon I, Hultborn H (1998) Flexor reflex afferents reset the step cycle during fictive locomotion in the cat. Exp Brain Res 122:339-350. CrossRef Medline

Simonsen EB, Dyhre-Poulsen P (1999) Amplitude of the human soleus H reflex during walking and running. J Physiol 515:929-939. CrossRef Medline

Simonsen EB, Alkjær T, Raffalt PC (2012) Reflex response and control of the human soleus and gastrocnemius muscles during walking and running at increasing velocity. Exp Brain Res 219:163-174. CrossRef Medline

Talpalar AE, Kiehn O (2010) Glutamatergic mechanisms for speed control and network operation in the rodent locomotor CpG. Front Neural Circuits 4: pii: 19. CrossRef Medline

Talpalar AE, Bouvier J, Borgius L, Fortin G, Pierani A, Kiehn O (2013) Dualmode operation of neuronal networks involved in left-right alternation. Nature 500:85-88. CrossRef Medline

Thibaudier Y, Frigon A (2014) Spatiotemporal control of interlimb coordination during transverse split-belt locomotion with 1:1 or 2:1 coupling patterns in intact adult cats. J Neurophysiol 112:2006-2018. CrossRef Medline

Van Wezel BM, Ottenhoff FA, Duysens J (1997) Dynamic control of location-specific information in tactile cutaneous reflexes from the foot during human walking. J Neurosci 17:3804-3814. Medline

Vasudevan EV, Bastian AJ (2010) Split-belt treadmill adaptation shows different functional networks for fast and slow human walking. J Neurophysiol 103:183-191. CrossRef Medline

Yang JF, Winter DA (1985) Surface EMG profiles during different walking cadences in humans. Electroencephalogr Clin Neurophysiol 60:485-491. CrossRef Medline

Zehr EP, Stein RB (1999) What functions do reflexes serve during human locomotion? Prog Neurobiol 58:185-205. CrossRef Medline

Zehr EP, Komiyama T, Stein RB (1997) Cutaneous reflexes during human gait: electromyographic and kinematic responses to electrical stimulation. J Neurophysiol 77:3311-3325. Medline

Zehr EP, Fujita K, Stein RB (1998) Reflexes from the superficial peroneal nerve during walking in stroke subjects. J Neurophysiol 79:848-858. Medline 